\title{
Assessment of the Feasibility of Implementing Shower Heat Exchangers in Residential Buildings Based on Users' Energy Saving Preferences
}

\author{
Sabina Kordana-Obuch *D, Mariusz Starzec (D) and Daniel Słyś (D) \\ Department of Infrastructure and Water Management, Rzeszow University of Technology, al. Powstańców \\ Warszawy 6, 35-959 Rzeszow, Poland; mstarzec1990@prz.edu.pl (M.S.); daniels@prz.edu.pl (D.S.) \\ * Correspondence: sk@prz.edu.pl
}

check for

updates

Citation: Kordana-Obuch, S.; Starzec, M.; Słyś, D. Assessment of the Feasibility of Implementing Shower Heat Exchangers in Residential Buildings Based on Users' Energy Saving Preferences. Energies 2021, 14, 5547. https://doi.org/10.3390/ en14175547

Academic Editor: José Carlos Magalhães Pires

Received: 16 July 2021

Accepted: 1 September 2021

Published: 5 September 2021

Publisher's Note: MDPI stays neutral with regard to jurisdictional claims in published maps and institutional affiliations.

Copyright: (C) 2021 by the authors Licensee MDPI, Basel, Switzerland. This article is an open access article distributed under the terms and conditions of the Creative Commons Attribution (CC BY) license (https:// creativecommons.org/licenses/by/ $4.0 /)$.

\begin{abstract}
In Poland, domestic hot water is heated mainly using fossil fuel energy sources. Such an approach results in the depletion of natural resources, pollution of the atmosphere and, consequently, irreversible changes to the climate. In response to this problem, this research identified the factors that most determine energy savings for heating water in residential buildings, as well as those that affect the choice of an alternative energy source. Additionally, the possibility of implementing shower heat exchangers in existing and newly built residential buildings was assessed, as well as society's willingness to use such devices. The research was carried out on a sample of 462 inhabitants of the Podkarpackie Voivodeship (Poland). A questionnaire survey was used as a tool. The conducted research has shown that the perspective of environmental protection is not a sufficient motivator to save energy for heating domestic hot water. It is necessary to implement appropriate programs aimed at informing the public about the possibilities offered by the use of alternative energy sources and co-financing the purchase of appropriate devices. In the case of drain water heat recovery systems, a significant problem is also the need to develop new, highly effective designs of shower heat exchangers which can be installed under the floor linear shower drain or on the horizontal shower waste pipe.
\end{abstract}

Keywords: Cramér's V coefficient; drain water heat recovery; greywater heat recovery; heuristics; measure of association; Podkarpackie Voivodeship; Poland; survey research

\section{Introduction}

All people, regardless of their origin, age or the environment in which they live, have a number of needs, the satisfaction of which is burdensome for the environment [1]. Some of them are constant and do not change over the years. Such needs include, among others, potable water [2]. Domestic hot water makes up an important part of the potable water used. Its heating is estimated to account for almost $20 \%$ of the average energy consumption in a household [3]. The share of hot water heating in the balance of energy consumption in a household may, however, be much higher and reach up to $30 \%$ [4]. In the case of hotels, it can be up to $40 \%$ [5]. Consequently, the heating of hot water contributes to significant emissions of carbon dioxide, methane, and other greenhouse gases into the atmosphere [6,7].

The energy consumption for water heating and the negative environmental impact of the system depends on many factors. These include climatic conditions [8]. The temperature of cold tap water changes throughout the year, which affects the energy demand [9]. The importance of the outside air temperature is also evident when using hot water tanks [10], especially if these devices are located in utility rooms or garages. In the winter season, the amount of hot water consumed is also increased [11]. Moreover, the amount of energy used for heating hot water is influenced by the type of device used and its energy efficiency [12]. The type of building [13], the preferences of system users with regard to 
the temperature of the water used [14], the number of users [15] and their environmental awareness [16] should also be considered important issues. The costs of water heating [17] and the use of a heat recovery system $[18,19]$ are also important.

However, regardless of the current level of energy consumption in a building, it is everyone's responsibility to search for alternative solutions that will improve the condition of the atmospheric air and at least slightly contribute to limiting climate change. Limiting the consumption of traditional fuels, mainly coal, will also be helpful in the fight against smog [20]. It is important not only for the sake of the environment, but also for the protection of human health [21]. Zimmermann et al. [22] additionally indicate that less centralized systems are more flexible and, as a result, adapt better to changing conditions. This is another incentive for the implementation of sustainable water heating systems within individual residential buildings. One of the main ways to reduce the consumption of fossil fuels is the increase in the use of renewable energy sources, which have long played an important role in the energy systems of the European Union [23]. In addition to sources that are used to heat domestic hot water, such as solar energy [24] or ground energy [25], attention should be paid to a third generation renewable energy source, which is warm wastewater [26]. Especially since energy is not the only valuable resource that can be recovered from wastewater, its use may also enable sustainable consumption of drinking water and the production of fertilizers $[27,28]$.

Greywater is especially valuable. The heat it carries is available all year round, and the potential for its use for heating hot water, unlike other renewable energy sources, increases in winter, when the cold water temperature is lowest and heating it requires the most energy. In the case of residential buildings, energy from greywater is recovered mainly by means of shower heat exchangers $[5,29,30]$. However, studies show that the heat source may also be the greywater discharged from other household appliances [31-33]. The process of heat recovery from wastewater can also be carried out in commercial kitchens [34] and sport facilities [35]. There are also examples of using wastewater as a lower energy source for heat pumps. The heat pump can then take heat only from wastewater [36] or use more heat sources [37]. The presented examples prove that the use of wastewater heat recovery systems in internal installations of buildings is technically justified. It should be noted, however, that heat pumps are mostly used in larger facilities, such as hotels [38] or hospitals [39]. Systems of this type can also be used within the wastewater collection system [40]. This is due to the fact that the coefficient of performance of the heat pump increases with the increase of the bath water flow rate [41]. In the case of individual residential buildings, the application of shower heat exchangers seems to be the only rational solution to reduce the consumption of fossil fuels and $\mathrm{CO}_{2}$ emissions. This is particularly important as water heating for bathing can account for up to $60 \%$ of the total $\mathrm{CO}_{2}$ emissions from residential water supply systems [42]. In the case of Poland, however, the lack of knowledge about the possibility of using this valuable resource remains a problem, as a result of which the heat energy carried by wastewater is usually irretrievably lost. The scarcity of shower heat exchangers in the local market is also a problem. Another significant factor is the too long period of return on investment, which in many cases exceeds the technical life of the device [43]. This is mainly due to the lack of promotion and funding of such solutions, both at the national and regional levels. Despite the fact that the financing of renewable energy sources in Poland has a smaller and smaller impact on the level of sustainable development [44], it should be remembered that the lack of financing pro-ecological installations may constitute a significant barrier to their implementation [45]. Therefore, it should be assumed that the implementation of heat recovery systems from wastewater will not be possible without the introduction of appropriate incentives and motivators, being a response to the real needs and preferences of residents. It is also necessary to recognize the energy-saving behaviors and awareness of installation users, as these factors may affect energy saving [46], and so far they have not been recognized in Poland. It is important to recognize which factors have the greatest impact on the propensity of society to save energy and to use alternative energy sources. So far, the 
attitude of society towards drain water heat recovery systems and their opinion on shower heat exchangers has not been recognized. The available literature lacks key information on the applicability of a given type of drain water heat recovery units in various buildings. It is also necessary to recognize the level of knowledge of the region's inhabitants in the field of drain water heat recovery systems.

Considering the above, the research attempted to identify the factors that determine the saving of energy used for heating water in residential buildings and the choice of an alternative energy source. Additionally, the article contributes to the current literature by assessing the possibility of using shower heat exchangers and the tendency of society to use such devices in residential buildings. In order to understand the situation, limitations and challenges, as well as to indicate solutions allowing for the increase in the use of shower water heat recovery systems, a survey was conducted on a sample of 462 inhabitants of the Podkarpackie Voivodeship. This region was selected as the subject of research because it is at the forefront of Polish regions in terms of the integrated measure of sustainable development in the area of environmental order [44]. The heuristics of average users of domestic hot water installations, being a procedure of unconscious, simplified inference [47], allowed for a relatively quick assessment of the situation and indication of an appropriate strategy in terms of increasing the possibilities of implementing shower water heat recovery systems.

The remainder of this paper is structured as follows. The next section describes the case study and the methodology of the research. Section 3 presents the results of the questionnaire surveys and their interpretation. The last section indicates the main findings of the research and the directions for further research.

\section{Materials and Methods}

\subsection{Case Study}

The research was conducted among the inhabitants of the Podkarpackie Voivodeship, which is located in the south-eastern part of Poland (Figure 1). This region covers an area of $17846 \mathrm{~km}^{2}$, which is $5.7 \%$ of the country's area. It is inhabited by 2.13 million people, of which almost $60 \%$ are rural residents [48]. The median age of people living in the studied region is 38.9 and 41.9 years, for men and women, respectively [48]. The research, the results of which are presented in the article, were conducted among people aged 18 and over. The required number of people in the sample was estimated based on the total number of inhabitants of the Podkarpackie Voivodeship with the established confidence level $\alpha=95 \%$. The population proportion was set at 0.5 and the margin of error-5\%. The designated required sample size is 384 people. The research was carried out on a group of 462 people. All data was collected anonymously.

For several years, the Podkarpackie Voivodeship has been in the top three Polish regions in terms of the integrated measure of sustainable development in the area of environmental order, which was already mentioned in the introduction. However, it should be emphasized that this is mainly due to the low level of sustainable development in other regions of the country [44]. The data presented in [49] show that the share of energy from renewable sources in the national energy consumption in the household sector is on average $17.5 \%$ in the European Union, while in Poland it is only $13.7 \%$. The same report [49] shows that the Podkarpackie Voivodeship is one of the regions characterized by a very unfavorable value of the energy poverty index, determined by the "High Costs, Low Income" method (13.31\% with the national average of $9.4 \%$ ), and by a relatively high indicator determined by the double median method $(17.79 \%$ with the national average of $17.2 \%$ ). Despite the fact that the values of these indicators have been gradually decreasing in recent years, they are still at a relatively high level in relation to the entire European Union [50]. It should also be emphasized that the average monthly gross salaries in the Podkarpackie Voivodeship are definitely lower than in other regions of Poland [48], while the unemployment rate reaches $8.5 \%$ [51]. In the enterprise sector, the average wages and salaries in the region slightly exceed 1000 EUR [51]. The data presented in [52] additionally 
show that the average monthly available income per capita is more than $17 \%$ lower than the national average and amounts to less than 350 EUR. As a consequence, the per capita expenditures of households are also the lowest in the country, amounting to around 200 EUR [52]. This problem is further exacerbated by the high energy prices, which in the case of electricity are around $0.16 \mathrm{EUR} / \mathrm{kWh}$. All this means that the expenses for housing, water electricity, gas and other fuels account for almost $19 \%$ of all expenses incurred by a statistical citizen in a household [52]. This provides an additional incentive to promote the wide use of renewable energy. The program for the development of renewable energy sources [53], which is in force in the Podkarpackie Voivodeship, describes the potential of various sources and indicates the possibility of their use in various economic sectors. However, there is no mention of energy recovery from wastewater. There are no programs in the voivodeship, as well as the whole country, aimed at promoting and financing the purchase and installation of shower heat exchangers.

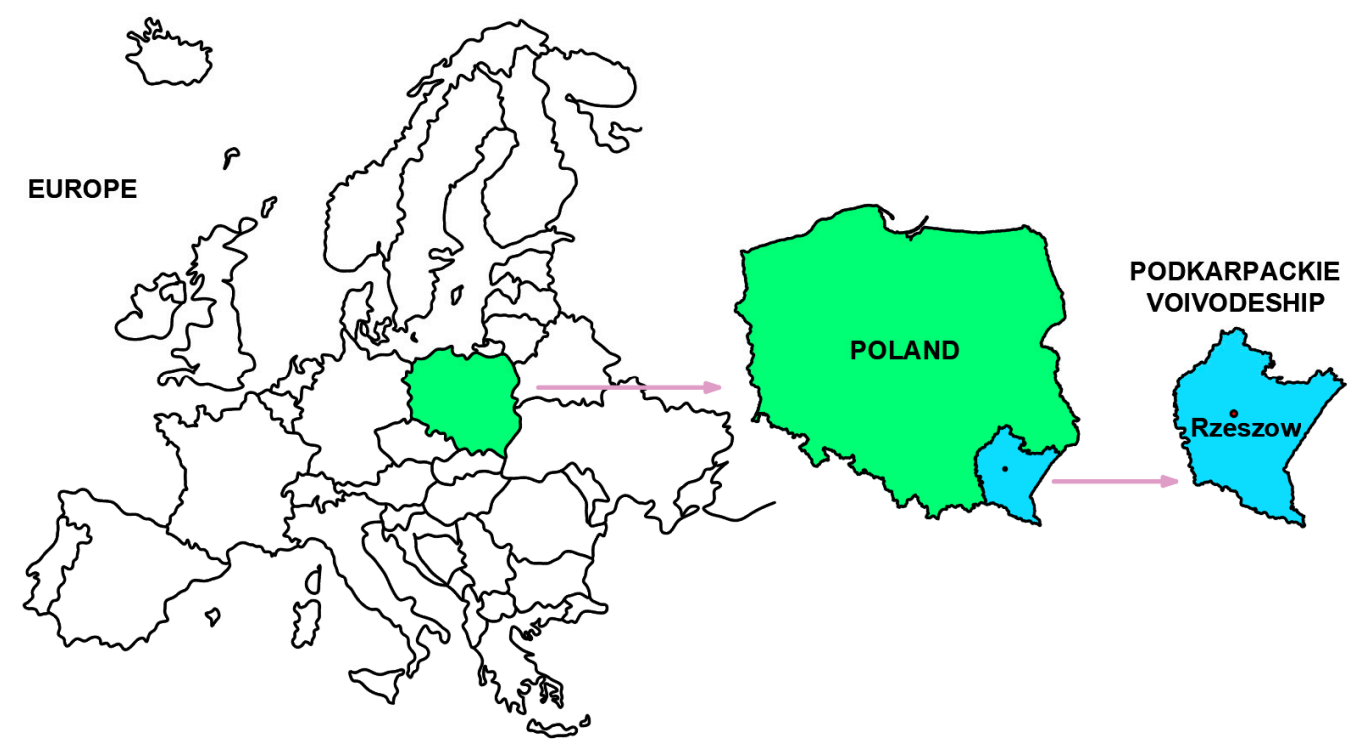

Figure 1. Location of the Podkarpackie Voivodeship on the map of Europe.

\subsection{Survey Research}

The identification of factors determining the saving of energy used for heating domestic hot water in residential buildings and influencing the choice of an alternative energy source, as well as the assessment of the possibility of implementing shower heat exchangers in such facilities, was possible thanks to the use of surveys. This method was chosen because it is flexible and can be used in a population of any size [54]. Thanks to this, questionnaire surveys have considerable statistical power, and their conduct allows for the collection of a large amount of information [55]. Surveys are widely used in various fields of the economy. They are also used when assessing the preferences of residents in terms of pro-ecological solutions related to energy. For example, Iliopoulos et al. [56] used the surveys to analyze the readiness of Japanese households to adopt demand respons programs. Gaspari et al. [57] conducted a survey that combined people's energy awareness and motivation, as well as their interactions with metering devices, into a coherent framework. Kim and Nam [58] modeled household investments in energy efficiency with time, risk and social preferences.

The successive stages of the research are presented in Figure 2. First, the state of the art in the field of domestic hot water heating systems used in Poland was analyzed and synthesized. For this purpose, a literature review was carried out and a number of interviews were conducted with both ordinary users of installations and persons professionally involved in plumbing installations. On this basis, a preliminary draft questionnaire was prepared, which was then tested, adjusted and validated by a team of experts. The result of the revision and the introduced improvements was the development of a questionnaire 
(Appendix A, Table A1), which was used in the research conducted in 2020-2021. The questionnaire was written and made available in Polish. It was divided into four parts, the first of which was aimed at general characteristics of the respondents. It included questions about age, gender, place of residence, education, type of residential building, energy sources used and the assessment of the hot water heating system.

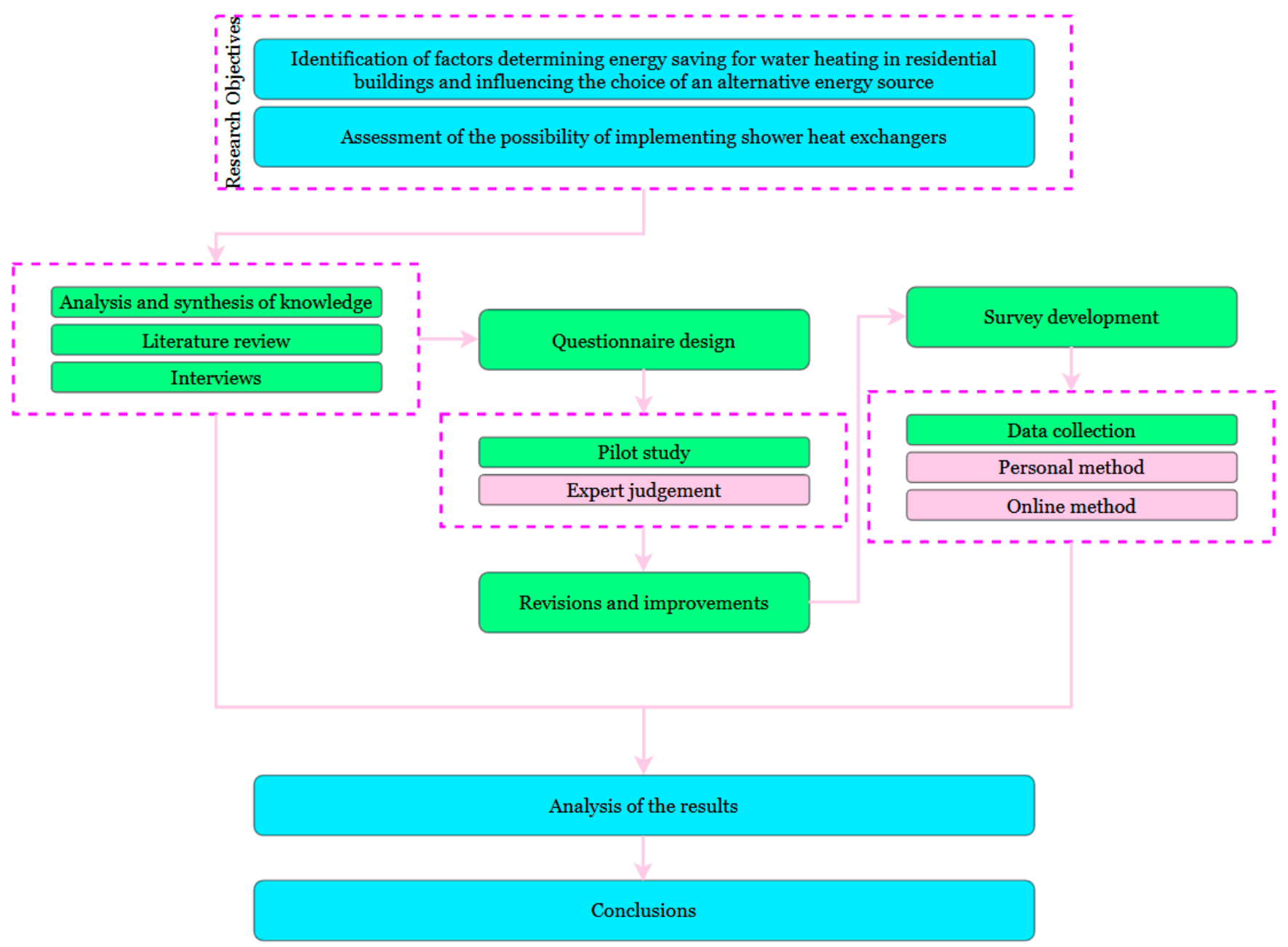

Figure 2. Research plan.

Subsequently, the preferences of the inhabitants of the Podkarpackie Voivodeship regarding the impact of various parameters on saving energy for hot water heating were checked. In the third part, these questions were detailed and related to the issue of choosing an alternative energy source. The last part dealt with the characteristics of the shower installation and the use of shower heat exchangers. The questions used a 5-point Likert scale, whereby the answers "definitely yes/good/high" scored " 5 " and "definitely no/poorly/low"-scored "1". A score of "3" corresponded to the answer "no opinion", which indicates a neutral attitude of the respondent to the question (neither yes/good/high nor no/poorly/low). This allowed for the determination of the mean $(M)$, median $(M e)$ and standard deviation $(S D)$. In both cases, the confidence intervals $(C I)$ were additionally determined with the assumed probability of $95 \%$. All values were determined using the Statistica software. For the mean $(M)$ and median $(M e)$, a score equal to or close to " 3 " may be interpreted as an index of intermediate feelings. This is especially true for those questions where a relatively small number of "no opinion" responses were obtained.

The Pearson's chi-squared test was also performed using the Statistica software. Based on the obtained values of $\chi^{2}$, the Cramér's $V$ (Cramér's $\varphi$ ) coefficients were determined. 
This made it possible to determine the level of association between the studied variables. The Cramér's $V$ coefficient is determined when at least one of the two compared variables takes more than two values. Its value ranges from 0 to 1 , and the closer the result is to 1 , the stronger the association between the examined variables. On the basis of [59], it can be concluded that 0.1 is the minimum threshold suggesting the existence of an association between two variables, and with values in the range $0.1-0.3$ there is a low association. Values of $0.3-0.5$ indicate moderate association, and when the Cramér's $V$ coefficient is greater than 0.5 , there is a high association. The Cramér's $V$ coefficient can be determined based on Equation (1) [59].

$$
V=\sqrt{\frac{\chi^{2}}{n \cdot \min (k-1, r-1)}}
$$

where: $\chi^{2}$-the result of the chi-square test, $n$-number of observations, $k$-number of columns in the contingency table, $r$-number of rows in the contingency table.

As many as 137 questionnaires were conducted using the personal method. Personal method of data collection is time-consuming, but allows to achieve higher response rates [55]. Direct contact with the respondents also allows them to ask additional questions. The answers obtained in this way were digitized. Due to the COVID-19 pandemic, the continuation of the research required a change in the adopted research method and the development of an online questionnaire. This questionnaire familiarized potential respondents with the most important information about shower heat exchangers and the basic diagrams of this type of installation. The respondents were familiarized with systems in which heat from the shower drain water is recovered by means of a vertical heat exchanger and by means of a heat exchanger located under the floor shower drain or on the horizontal shower waste pipe. The presentation of the main elements of the heat recovery system in the diagrams made it possible to make the respondents aware of the requirements regarding the availability of space for the installation of various types of heat exchangers. Attention was also paid to the scope of required installation works and possible ways of leading preheated water lines depending on the type of the main source of hot water in the building. It was emphasized that the costs of assembly, and in the case of existing buildings, also changes in the finishing of the bathroom or other room with a shower, constitute a significant part of the capital expenditure to be incurred to implement the drain water heat recovery system. The respondents were also informed about the purchase costs of shower heat exchangers, their effectiveness and the factors determining the expected payback period. In this way, responses from 325 people were received. The results obtained using both methods were included in the analysis jointly.

\subsection{Shower Heat Exchangers}

The last part of the questionnaire concerns the characteristics of the shower installation and the use of shower heat exchangers. These are devices whose task is to transfer the waste heat deposited in the shower drain water to the tap water flowing into the shower system [60]. Depending on the method of conducting installations and the availability of space for the installation of a heat recovery system, vertical and horizontal heat exchangers as well as devices installed under the floor shower drain can be used [61]. The water preheated in the heat exchanger can be led to the domestic hot water heater and/or directly to the shower mixing valve [62].

The use of energy that is usually irretrievably lost saves fossil fuel resources and reduces greenhouse gas emissions. These devices operate virtually maintenance-free and do not affect the feeling of shower users. Moreover, the operation of shower heat exchangers does not require external energy supply, therefore they do not cause additional $\mathrm{CO}_{2}$ emissions during operation.

The cost of purchasing such a device can vary widely. Mazhar et al. [63] indicate, that in a case of the most popular highly efficient vertical heat exchangers, it can exceed 1000 EUR. 
However, there are models available on the world market, the cost of which amounts to several hundred euros. In the case of plate heat exchangers, the price of the device is typically 350-2300 EUR [63]. There are also known designs of shower heat exchangers, installed on the horizontal shower waste pipe, which cost no more than 100 EUR [9]. However, their efficiency is definitely lower than that of vertical heat exchangers. The efficiency of the vertical heat exchanger can be as high as 30 to $60 \%$, while the efficiency of some horizontal heat exchangers does not exceed a dozen or so percent [9]. Due to the need to install heat exchangers below the shower drain and the considerable length of the vertical units, in some cases, however, installation of such a heat exchanger may not be feasible, especially in existing buildings. The expenditures also include the cost of assembly and modification of the existing plumbing installation, the amount of which depends on the distance of the domestic hot water heater from the heat exchanger and the method of conducting internal installations in the building. In the case of existing buildings, an additional increase in expenditure results also from the need to dismantle and reconstruct wall and floor elements (Table 1). The average payback period in the case of using a shower heat exchanger is from a few to several years, and depends, apart from total capital expenditures, on the amount of water used, device efficiency and energy costs. In the case of gas water heaters, it may elongate [43].

Table 1. The average expenditures to be incurred for the implementation of shower heat exchangers in Polish conditions.

\begin{tabular}{ccc}
\hline & \multicolumn{2}{c}{ The Amount of Expenditure } \\
\cline { 2 - 3 } Type of Expenditure & Horizontal Shower Heat Exchanger & Vertical Shower Heat Exchanger \\
\cline { 2 - 3 } & Existing buildings \\
\hline Dismantling of wall and floor elements & $30-70$ & $30-200$ \\
Modification of existing plumbing installation & $100-250$ & $200-500$ \\
Purchase of shower heat exchanger & $100-800$ & $500-1600$ \\
Reconstruction of wall and floor elements & $120-280$ & $120-1100$ \\
Total expenditure & $350-1400$ & $850-3400$ \\
\hline & Newly designed buildings & - \\
\hline Dismantling of wall and floor elements & - & $150-450$ \\
Modification of the design of plumbing & $50-200$ & $900-1600$ \\
Purchase of shower heat exchanger & $100-800$ & - \\
Total expenditure & - & $1050-2050$
\end{tabular}

Theoretically, all models of shower heat exchangers can be installed in any way. However, in practice, in exchangers installed under the floor shower drain or on the horizontal shower waste pipe, due to their location directly below the shower, water is usually heated, which then flows to the tap (Figure 3). In other cases, the devices are located in a separate room, for example in a basement or a technical room on the lower floor, which makes the other two possible solutions more cost-effective, which involve supplying pre-heated water to the domestic hot water heater (Figure 4). 


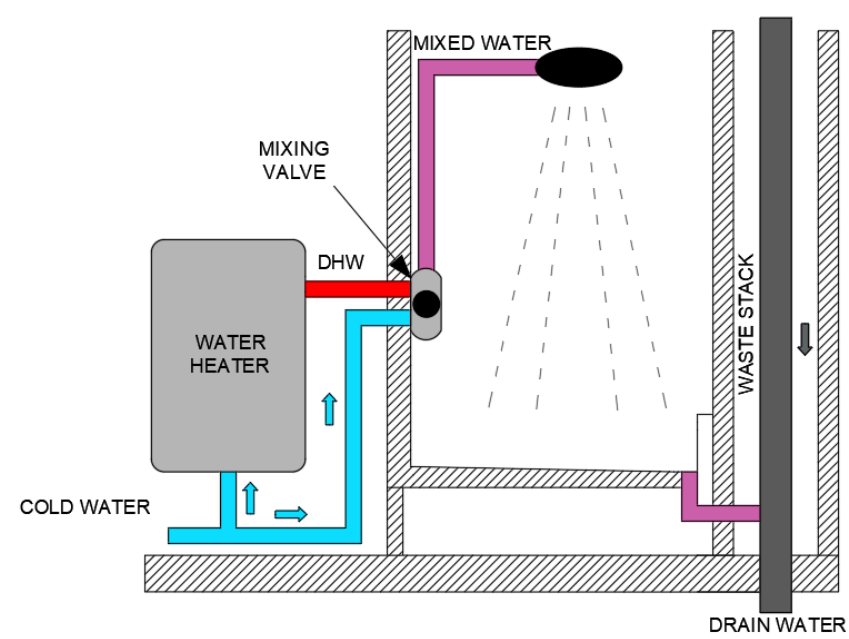

(a)

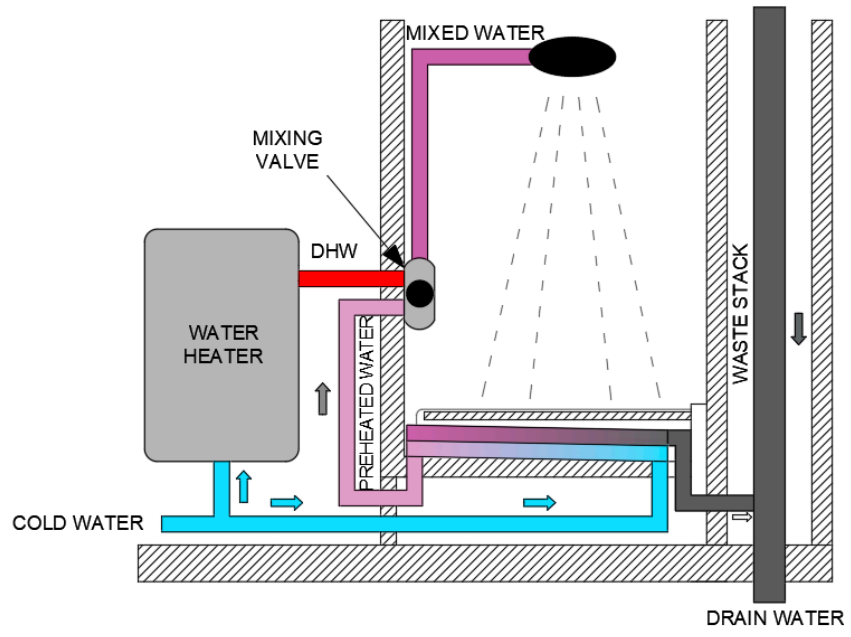

(b)

Figure 3. Installation example of a heat exchanger mounted under the floor shower drain: (a) Installation without a shower heat exchanger; (b) Installation with a shower heat exchanger (DHW—domestic hot water).

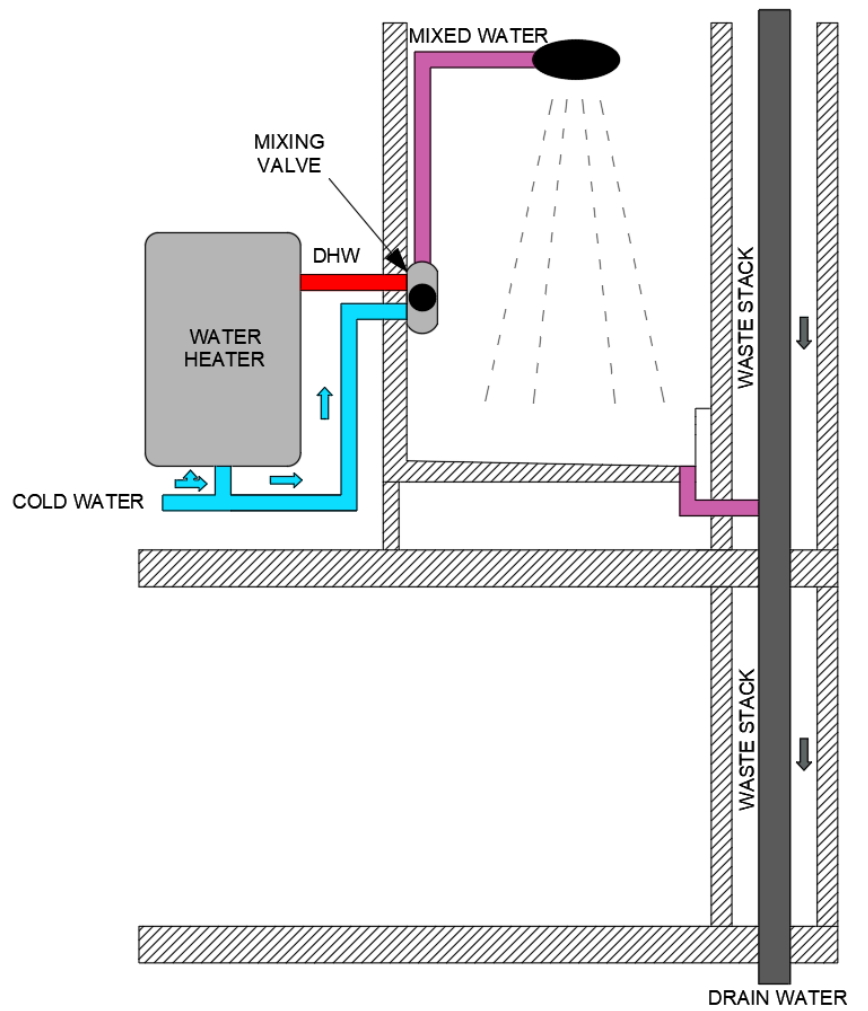

(a)

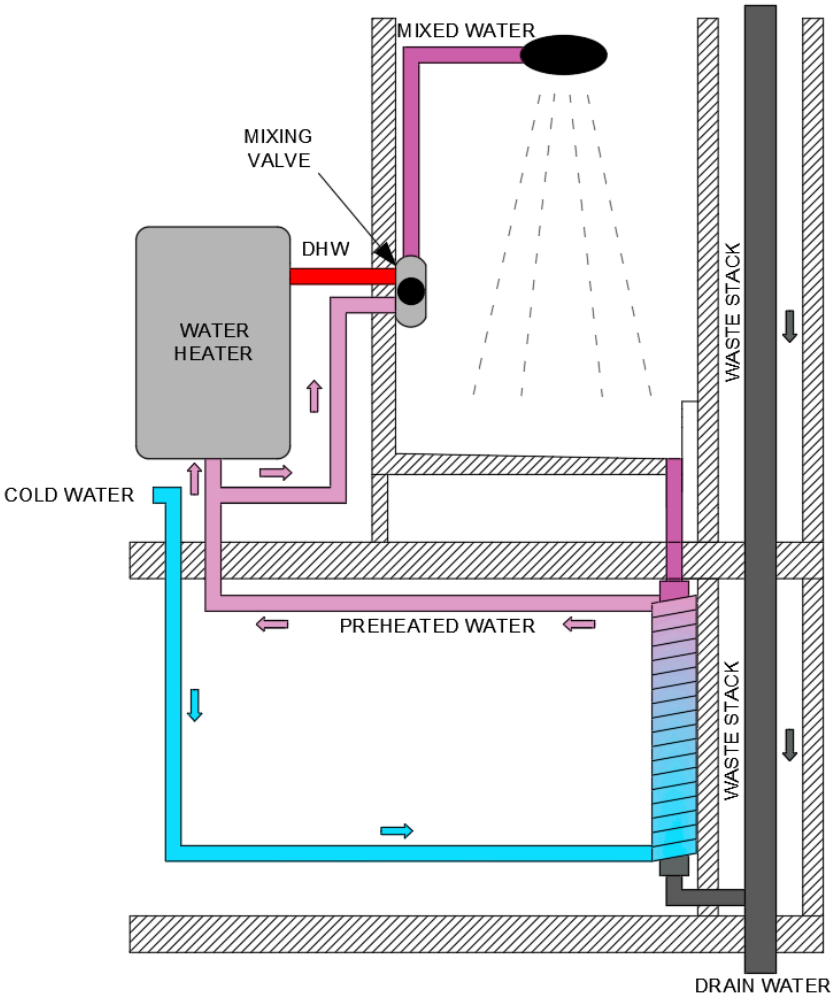

(b)

Figure 4. Installation example of a vertical heat exchanger: (a) Installation without a shower heat exchanger; (b) Installation with a shower heat exchanger (DHW-domestic hot water).

Savings resulting from the use of a shower heat exchanger depend on the amount of water used for a shower, the efficiency of the heat exchanger with the given conditions of water and drain water flow through this device and the temperatures of both media. Table 2 summarizes the energy savings resulting from the use of a shower heat exchanger, which were determined on the basis of the authors' calculation model, described in detail in [64]. Financial savings were calculated assuming energy prices for Rzeszow (Podkarpackie 
Voivodeship, Poland). In the case of electricity it is $0.75 \mathrm{PLN} / \mathrm{kWh}(\approx 0.16 \mathrm{EUR} / \mathrm{kWh})$, in the case of natural gas- $0.25 \mathrm{PLN} / \mathrm{kWh}(\approx 0.05 \mathrm{EUR} / \mathrm{kWh})$. The calculations assume temperatures that are commonly adopted in Polish conditions for dimensioning internal plumbing systems: cold water temperature $T_{c w}=10^{\circ} \mathrm{C}$, mixed water temperature $T_{m w}=40^{\circ} \mathrm{C}$, hot water temperature $T_{h w}=55^{\circ} \mathrm{C}$. The temperature of drain water discharged from the shower is in this case $T_{d w}=38^{\circ} \mathrm{C}$. The efficiency of the hot water heater was assumed at the level of $\eta=95 \%$. It has been assumed that the preheated water will be supplied to both the hot water heater and the shower's mixing valve. The selected variant of the installation of the shower heat exchanger is the most advantageous solution in terms of the amount of energy recovered from drain water [64]. The water consumption for showering was assumed at $35 \mathrm{~L}$ per person per day [65]. The results of the calculations show that the efficiency of the heat exchanger and the amount of water used have a key impact on the amount of energy recovered from drain water, and consequently also on the reduction of greenhouse gas emissions. While it is not advisable to increase the amount of water used, increasing the efficiency of heat exchangers is desirable from the point of view of both the consumers and the environmental protection.

Table 2. The effects of using a shower heat exchanger in a single-family building (SHE—shower heat exchanger, GWH—gas water heater, EWH-electric water heater).

\begin{tabular}{|c|c|c|c|c|c|c|}
\hline \multirow{2}{*}{$\begin{array}{l}\text { Water Consumption } \\
\text { for Showering }\end{array}$} & \multirow{2}{*}{$\begin{array}{l}\text { Efficiency } \\
\text { of the SHE }\end{array}$} & \multirow{2}{*}{$\begin{array}{l}\text { Annual Energy } \\
\text { Savings }\end{array}$} & \multicolumn{2}{|c|}{ Annual Financial Saving } & \multicolumn{2}{|c|}{ Annual Reduction of $\mathrm{CO}_{2}$ Emissions } \\
\hline & & & GWH & EWH & GWH & EWH \\
\hline L Per Day & $\%$ & kWh & $€$ & $€$ & kg & $\mathrm{kg}$ \\
\hline \multirow{5}{*}{35} & 20 & 88 & 4 & 14 & 17 & 63 \\
\hline & 30 & 131 & 7 & 21 & 26 & 94 \\
\hline & 40 & 175 & 9 & 28 & 35 & 126 \\
\hline & 50 & 219 & 11 & 35 & 44 & 157 \\
\hline & 60 & 262 & 13 & 42 & 52 & 188 \\
\hline \multirow{5}{*}{70} & 20 & 175 & 9 & 28 & 35 & 126 \\
\hline & 30 & 263 & 13 & 42 & 52 & 189 \\
\hline & 40 & 350 & 17 & 56 & 70 & 252 \\
\hline & 50 & 437 & 22 & 70 & 87 & 314 \\
\hline & 60 & 524 & 26 & 84 & 104 & 377 \\
\hline \multirow{5}{*}{105} & 20 & 263 & 13 & 42 & 52 & 189 \\
\hline & 30 & 394 & 20 & 63 & 79 & 283 \\
\hline & 40 & 525 & 26 & 84 & 105 & 377 \\
\hline & 50 & 656 & 33 & 105 & 131 & 472 \\
\hline & 60 & 786 & 39 & 126 & 157 & 565 \\
\hline \multirow{5}{*}{140} & 20 & 350 & 18 & 56 & 70 & 252 \\
\hline & 30 & 525 & 26 & 84 & 105 & 378 \\
\hline & 40 & 700 & 35 & 112 & 139 & 503 \\
\hline & 50 & 874 & 44 & 140 & 174 & 629 \\
\hline & 60 & 1048 & 52 & 168 & 209 & 753 \\
\hline \multirow{5}{*}{175} & 20 & 438 & 22 & 70 & 87 & 315 \\
\hline & 30 & 657 & 33 & 105 & 131 & 472 \\
\hline & 40 & 875 & 44 & 140 & 174 & 629 \\
\hline & 50 & 1093 & 55 & 175 & 218 & 786 \\
\hline & 60 & 1310 & 65 & 210 & 261 & 942 \\
\hline \multirow{5}{*}{210} & 20 & 526 & 26 & 84 & 105 & 378 \\
\hline & 30 & 788 & 39 & 126 & 157 & 567 \\
\hline & 40 & 1050 & 52 & 168 & 209 & 755 \\
\hline & 50 & 1312 & 66 & 210 & 261 & 943 \\
\hline & 60 & 1572 & 79 & 251 & 313 & 1130 \\
\hline
\end{tabular}


The amount of saved energy determines the reduction of greenhouse gas emissions to the atmosphere. Table 2 and Figure 5 show the annual reduction in carbon dioxide $\left(\mathrm{CO}_{2}\right)$ emissions depending on the energy savings for showering in households. The emission factor for end users of electricity is based on [66]. It amounts to $719 \mathrm{~kg} / \mathrm{MWh}$. In the case of natural gas, the data presented in [67] were used, according to which the emission factor for this fuel is less than $200 \mathrm{~kg} / \mathrm{MWh}$. The reduction of emissions from individual residential buildings is not significant. However, if shower heat exchangers were installed in more buildings, the environmental benefits would be noticeable. The presented calculation results also show that the use of shower heat exchangers is particularly advantageous when domestic hot water is heated with an electric water heater. This is due to the fact that electricity in Poland is mainly produced from coal.

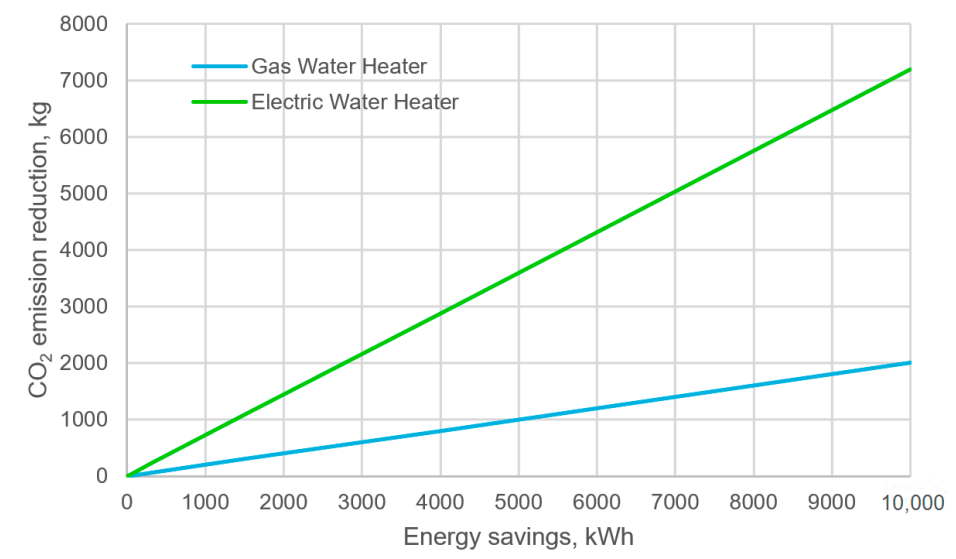

Figure 5. $\mathrm{CO}_{2}$ emission reduction resulting from the installation of shower heat exchangers.

\section{Results and Discussion}

\subsection{Demographics $\mathcal{E}$ Households Characteristics}

In the first part of the survey, concerning demographics \& households characteristics, respondents were asked about their age, gender, place of residence, type of residential building and education, as well as the type of hot water heating system used. The results are summarized in Figure 6. They show that the majority of the respondents were young people, as approximately $65 \%$ of the respondents were under 40 years of age. It should be noted, however, that it is people at a young age who will build houses in the future and it is in their hands to increase the degree of implementation of shower heat exchangers. The answers provided by the respondents also show that slightly more women than men (54.5\%) took part in the survey, which roughly corresponds to the demographic structure of the Podkarpackie Voivodeship. The data presented in [48] show that women constitute on average about $51 \%$ of the inhabitants of the voivodeship. In some regions, however, this share is definitely higher. The data presented in the "Statistical Atlas of Podkarpackie Voivodeship" [48] also show that almost 59\% of the population lives in villages. In the case of respondents participating in the survey, it was approx. 60\%. About $80 \%$ of the respondents declared that they lived in a single-family or terraced house, which creates a wide range of applications for individual wastewater heat recovery systems. About 19\% of the respondents stated that they had a master's degree, and around 20\% a bachelor's degree. The remaining persons declared that they completed their education at a lower level. 


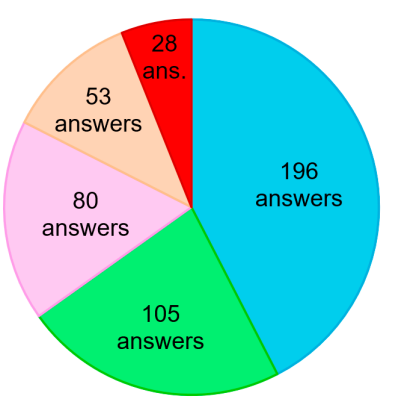

(a)

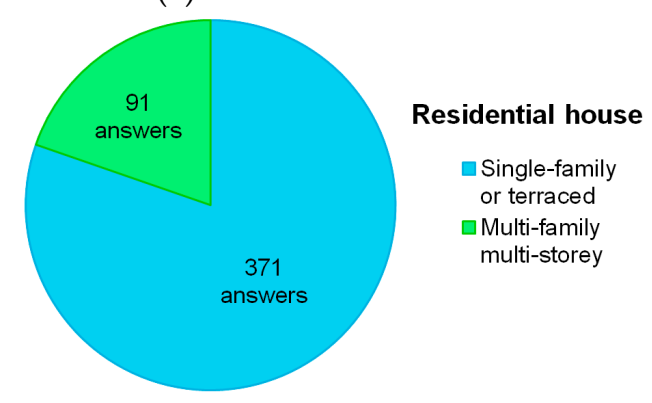

(d)

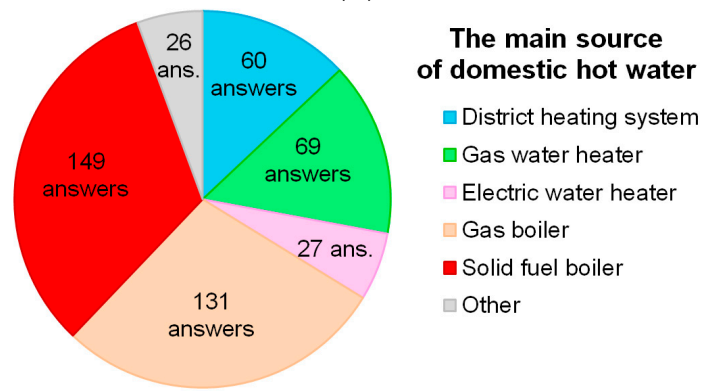

(f)

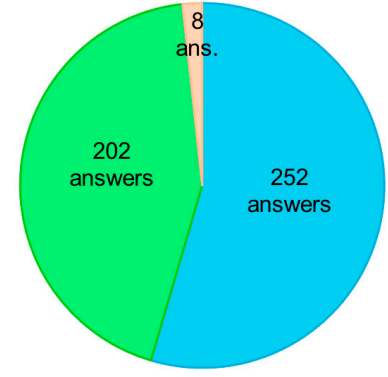

(b)

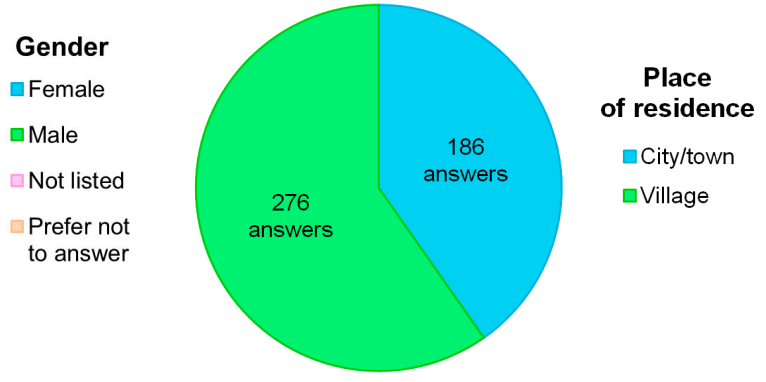

(c)

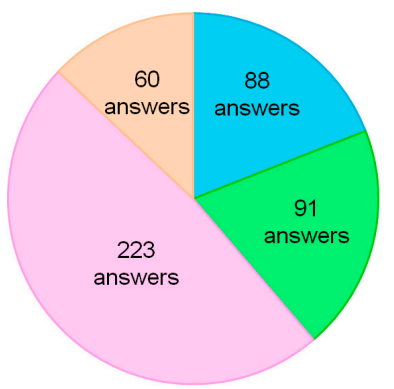

Education

- Master's

degree

degree

degree

Professional

certification

(e)

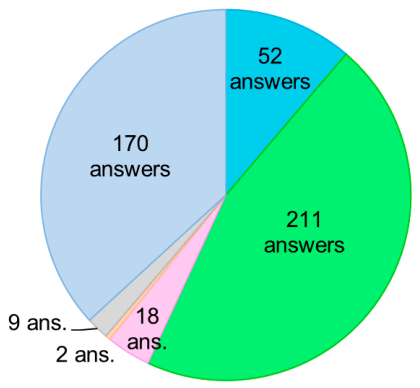

Additional device

for heating water

Device that uses fossil

energy sources

- Solar panels

Heat pump

Biomass boiler

- Shower heat exchanger

Other renewable energy source device

(g)

Figure 6. Characteristics of the respondents and their water heating systems: (a) Age; (b) Gender; (c) Place of residence; (d) Residential house; (e) Education; (f) The main source of domestic hot water; (g) Additional device for heating water.

The analysis of domestic hot water heating systems has shown that the inhabitants of the Podkarpackie Voivodeship rely mainly on fossil energy sources. Over $32 \%$ of the respondents heat their water with the help of solid fuel boiler, and about $28 \%$-gas boiler. The third place in the ranking was taken by gas water heater with a share of less than $15 \%$. The district heating system came in fourth. This is due to the fact that villagers are forced to heat water with individual heat sources due to the lack of heating networks in the vicinity of their place of residence. Furthermore, in the case of urban areas, a connection to the heating network is in many cases not technically and financially justified. The results differ significantly from those published by Statistics Poland for the whole country [49]. These differences most probably result from the fact that the majority of the inhabitants of the Podkarpackie Voivodeship are people living in rural areas, while the country's share of rural residents is only $40 \%$ [68]. The research also showed that electric water heaters are used by less than $6 \%$ of the respondents. This result should be considered unfavorable from the point of view of implementing shower heat exchangers. The conducted research $[43,69]$ shows that the use of wastewater heat recovery systems is particularly profitable when domestic hot water is heated with an electrically powered device. In the case of hot water heaters, it is also possible to supply preheated water to both the shower mixing valve and the heater, which is the most cost-effective solution. In the case of other options, e.g., solid fuel boilers or district heating systems, the only rational solution seems to be heat recovery for the purpose of heating the water supplied only to the shower mixing valve. However, the use of such a solution results in a reduction of the amount of recovered 
energy as compared to the situation when the entire water used in the shower installation is preheated in the heat exchanger [70].

The conducted research also showed that over $60 \%$ of respondents have an additional device dedicated to heating hot water in the building. Over $80 \%$ of them are devices that use renewable energy sources, which can be considered a satisfactory result. In most cases, these are solar collectors. Over $45 \%$ of the respondents admitted having them. Such a large number of systems dedicated to the use of solar energy is probably the result of programs co-financing the purchase of these devices. These programs have been implemented in recent years both in the country and in the Podkarpackie Voivodeship. However, none of the respondents indicated a shower heat exchanger as an additional device for heating water. Therefore, it can be concluded that these systems are not popular among the inhabitants of the region.

In the first part of the survey, the respondents also expressed their opinion on domestic hot water heating systems. On the basis of the obtained answers (Figure 7) it can be concluded that approximately $90 \%$ of the inhabitants assess their domestic hot water heating system positively $(Q 8)$. Only $4.5 \%$ of the respondents chose the answer "rather poorly", and none of them assessed the exploited system definitely poorly. The vast majority of users do not experience any inconvenience associated with the domestic hot water heating system $(Q 10)$. A high degree of satisfaction with the systems currently used may, therefore, be the reason for the lack of willingness to look for alternative solutions. The situation is different for the costs of hot water heating incurred by the users (Q9). Only $32 \%$ of the respondents admitted that their energy bills for heating hot water are acceptable for them, while the answer "definitely yes" was indicated by only $20 \%$ of them. Therefore, an opportunity for shower heat exchangers implementation should be seen in the reduction of hot water heating costs, especially since only a small part of the respondents $(24 \%)$ see a problem with access to fossil fuels (Q11).

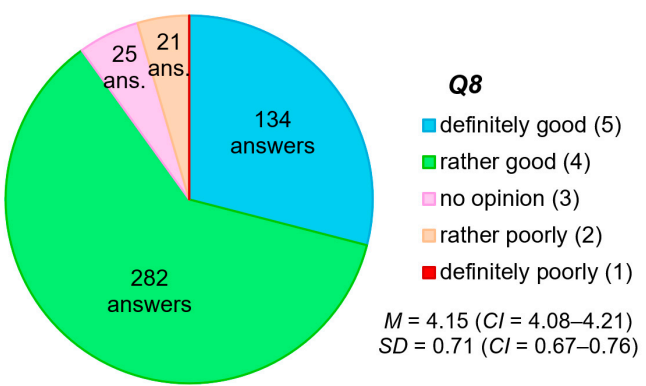

(a)

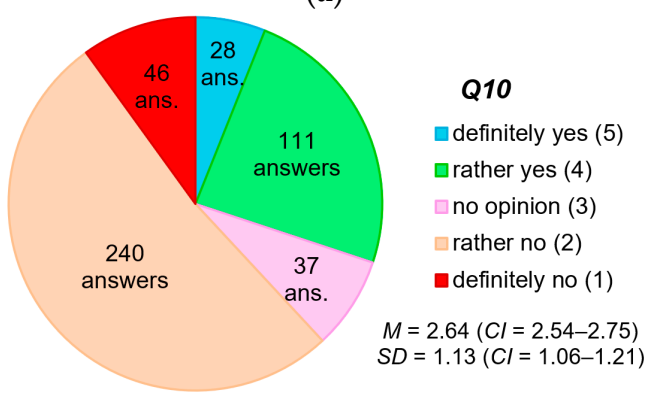

(c)

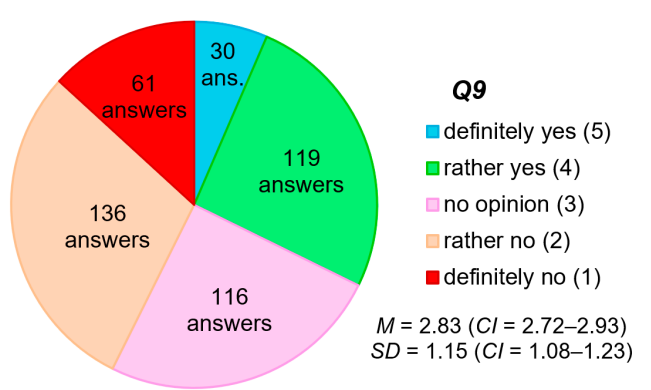

(b)

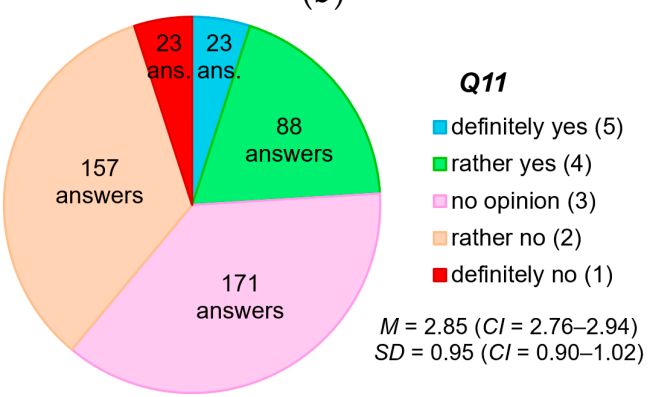

(d)

Figure 7. Evaluation of domestic hot water heating systems ( $M$-average, $S D$-standard deviation, $C I$-confidence interval; questions numbers $(Q)$ according to the Appendix A): (a) question $Q 8$; (b) question $Q 9$; (c) question $Q 10$; (d) question $Q 11$.

\subsection{Factors Determining Energy Saving for Water Heating}

In the next part of the survey, the respondents assessed the factors determining energy saving for water heating. The results are presented in Figure 8. It shows that all factors 
were considered by the respondents as important from the point of view of energy saving. In each case, over $60 \%$ of the respondents indicated the answer "definitely yes" or "rather yes", and the median answer $(M e)$ was " 4 ". In the opinion of the respondents, however, the most important factor is the increase in the comfort and safety of using the installation (Q15). Over $90 \%$ of the respondents admitted that it could contribute to saving energy for heating domestic hot water in residential buildings. A slightly lower share of affirmative responses $(89 \%)$ was obtained in the question regarding technical issues related to the installation and use of the system and the availability of an energy source (Q16). In both cases, the mean of the answers $(M)$ exceeded 4 . It should also be noted that in the case of questions $Q 15$ and $Q 16$, the answers were the least differentiated $(S D \leq 0.7)$. Considering the above, it can be expected that drain water heat recovery systems have wide application possibilities. Heat from greywater is available all year round, also in winter, when the possibilities of obtaining other renewable energy sources are limited. Additionally, increasing the temperature of the water supplied to the hot water heater would increase the efficiency of the device and the comfort of using the installation provided with a tankless hot water heater.

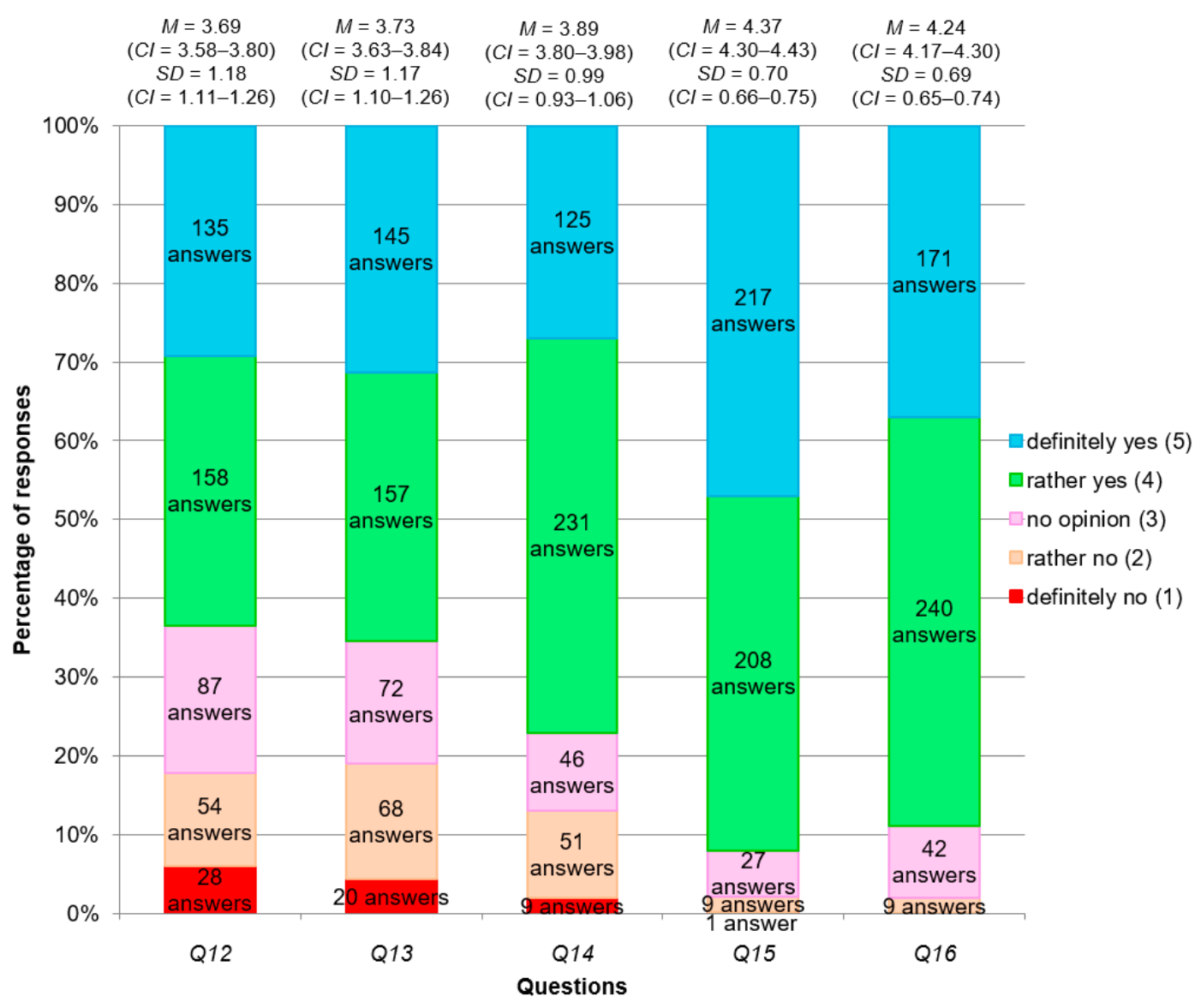

Figure 8. Assessment of factors determining energy saving for heating water in residential buildings $(M-$ average, $S D$ standard deviation, $\mathrm{CI}$-confidence interval; questions numbers $(Q)$ according to the Appendix $A)$.

Over $85 \%$ of the respondents declared that the introduction of legal regulations imposing energy saving and reduction of greenhouse gas emissions (Q14) would be a motivating factor to save energy for heating domestic hot water. Considering that energy consumption in Poland is mostly based on fossil energy sources, which results in a high environmental effect and an increase in social costs related to excessive $\mathrm{CO}_{2}$ emissions [71], the legislator should think about this possibility. However, it is important to consider the need to recover heat from wastewater in the regulations being developed. The "Energy Policy of Poland until 2040" [72], which was adopted this year, emphasizes the need to use 
renewable energy sources, but does not include greywater or other types of wastewater among these sources.

The least important factor was the possibility of protecting the environment and natural resources $(Q 12)$. The mean response $(M)$ in this case was only 3.69 , and the obtained responses were highly diversified $(S D=1.17)$. This confirms that the mere prospect of improving the condition of the natural environment is not a sufficient argument to encourage users to save energy. In order to increase the implementation of sustainable systems, it is necessary to introduce appropriate incentives and motivators. A slightly higher result $(M=3.73)$ was obtained by the factor relating to economic benefits $(Q 13)$. Additionally, in this case, the responses were significantly differentiated, which probably results from the differentiation of income of individual households. The share of people who did not consider economic benefits to be significant, however, is similar to the share of respondents for whom the energy bills for heating water are acceptable. It should also be noted that only 20 respondents stated that the economic benefits would definitely not encourage them to save energy for heating domestic hot water, which is only $4 \%$ of all respondents.

\subsection{Factors Influencing the Choice of an Alternative Energy Source}

In line with the research methodology described in Section 2.2, the issues described in Section 3.2 were detailed in the next part of the questionnaire and related to the selection of an alternative energy source. The obtained results are shown in Figures 9-13.

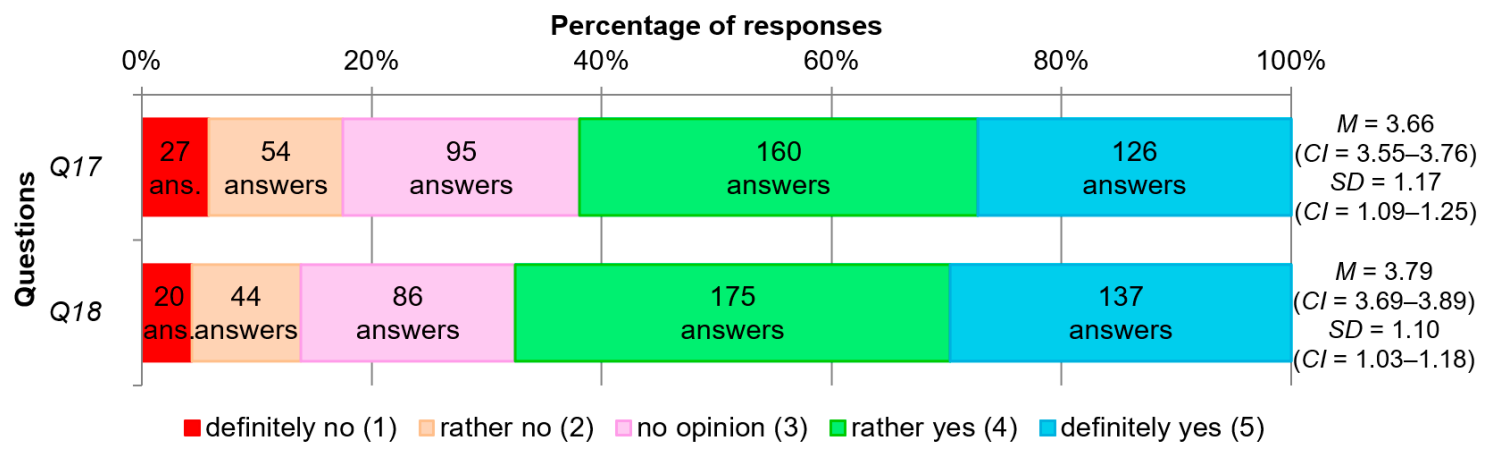

Figure 9. Assessment of environmental factors influencing the choice of an alternative energy source for heating water in residential buildings $(M$-average, $S D$ —standard deviation, $C I$ —confidence interval; questions numbers $(Q)$ according to the Appendix A).

As in the case of factors determining energy saving for water heating, the respondents considered the least important factors related to the protection of the environment and natural resources (Q17 and Q18). Although most of them admitted that they would have an impact on the choice of an alternative energy source, the answer "definitely yes" was marked in both cases by less than $30 \%$ of the respondents (Figure 9). It should also be noted that the respondents rated the need to conserve natural resources slightly higher $(Q 18)$ than the possibility of reducing greenhouse gas emissions $(Q 17)$. This confirms that environmental issues are not the main determinant of the choice of energy source for domestic hot water heating in Poland. It is therefore necessary to promote a sustainable lifestyle among the youngest generations. Appropriate education could contribute to a change in the perception of the issue of environmental protection in the coming years.

As part of the research, economic issues were also analyzed, and the results are summarized in Figure 10. Contrary to the results obtained in the previous part of the questionnaire (Section 3.2), in this case, the respondents considered economic issues to be very important, and the answers were not very diverse $(S D \leq 0.83)$. It can therefore be concluded that if the user is already determined to save energy, the financial issues will have a decisive influence on the choice of a specific energy source. The most important aspect was the possibility of obtaining financing for the purchase of the system $(Q 23)$. Over 
93\% of the respondents declared that this factor would have an impact on the choice of a specific system, and approximately $64 \%$ chose the option "definitely yes". It is therefore necessary to implement programs dedicated to promoting and co-financing the purchase of shower heat exchangers. Although many programs are currently being implemented in the country to finance pro-ecological installations, none of them covers the purchase of this device. It is obvious, therefore, that the inhabitants of both the Podkarpackie Voivodeship and the whole country will choose a solution, the purchase of which will be at least partially financed by other institutions. An example can be solar collectors, the possession of which is declared by almost $46 \%$ of the respondents. Providing an appropriate source of financing for the purchase of shower heat exchangers would certainly increase the interest in using these devices.

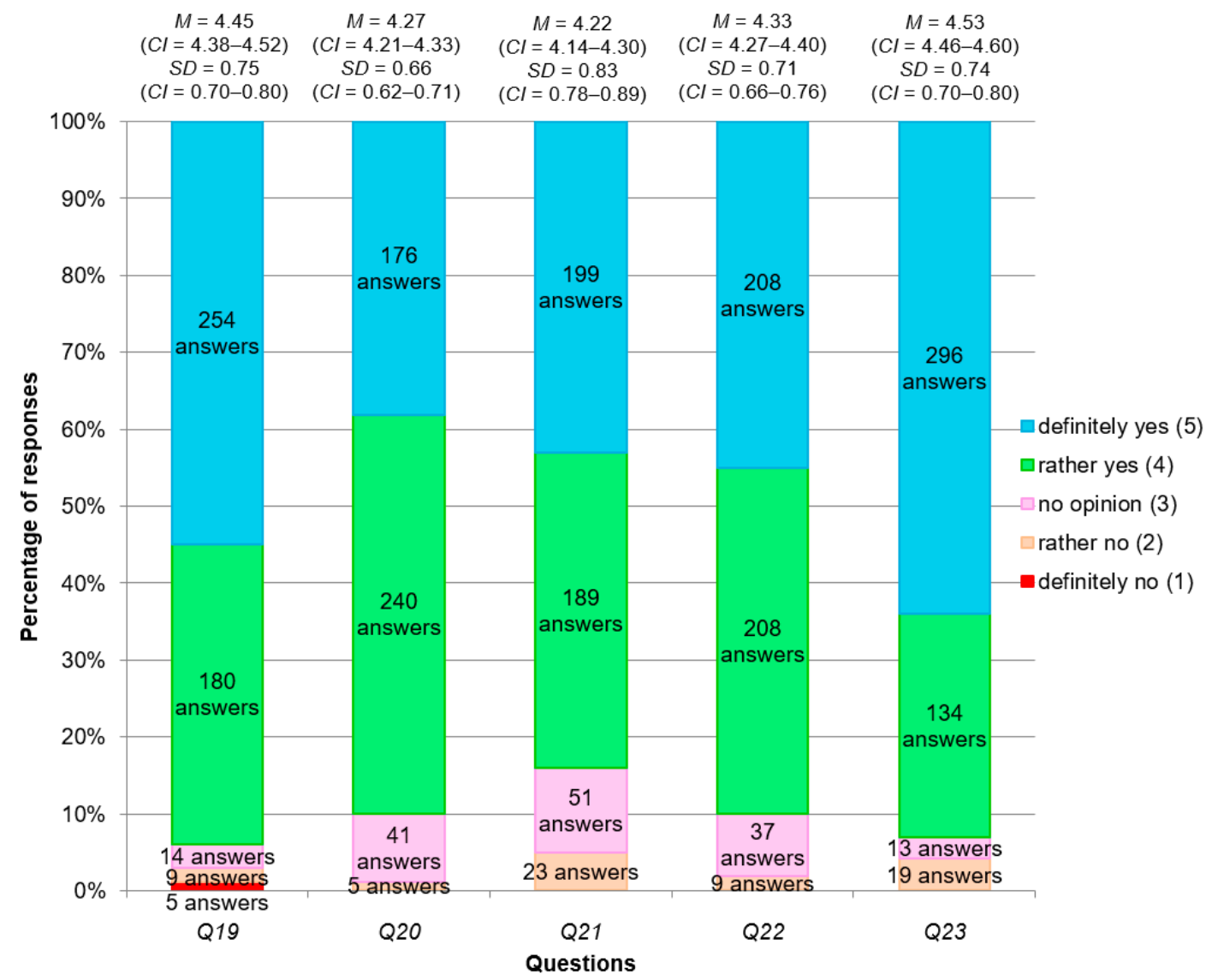

Figure 10. Assessment of economic factors influencing the choice of an alternative energy source for heating water in residential buildings ( $M$-average, $S D$ —standard deviation, $C I$-confidence interval; questions numbers $(Q)$ according to the Appendix A).

The respondents considered the cost of purchasing and assembling the device to be equally important (Q19), giving it an average rating of $M=4.45$. As in the case of question $Q 23$, the median answer $(M e)$ was 5 . Therefore, it is important to develop new designs of shower heat exchangers, the price of which will be adequate to the budget of an average household. The devices that are currently available on the Polish market are characterized by a relatively high price and, at the same time, low efficiency, which certainly discourages potential users from purchasing them. Factors relating to the unit costs of water heating $(Q 20)$, the costs of maintenance and possible repair of the system $(Q 21)$ and the expected service life of the system $(Q 22)$ were also considered important from the point of view of the selection of the energy source for domestic hot water heating. Therefore, the designed devices should not only be relatively cheap, but also have high efficiency, durability and resistance to contaminants present in greywater. The data of the Patent Office of the Republic of Poland [73] show that in recent years a number of heat 
exchangers dedicated to heat recovery from greywater have been patented in the country, but these solutions have not been commercialized. This is mainly due to the lack of public interest in wastewater heat recovery systems. Once again, therefore, it is necessary to emphasize the need to promote the idea of recovering waste heat deposited in greywater for domestic hot water heating.

Legal issues (Figure 11) were rated only slightly higher than environmental issues. They therefore do not have a decisive influence on the choice of an energy source for heating water. However, it should be noted that both in the case of regulations relating to the use of a specific energy source $(Q 24)$ and those related to the need to reduce greenhouse gas emissions $(Q 25)$, less than $10 \%$ of the respondents indicated that these issues will not be considered. The answer "definitely no" was chosen by less than $5 \%$ of the respondents. Therefore, it can be assumed that the introduction of appropriate legal regulations could also contribute to an increase in the implementation of shower heat exchangers.

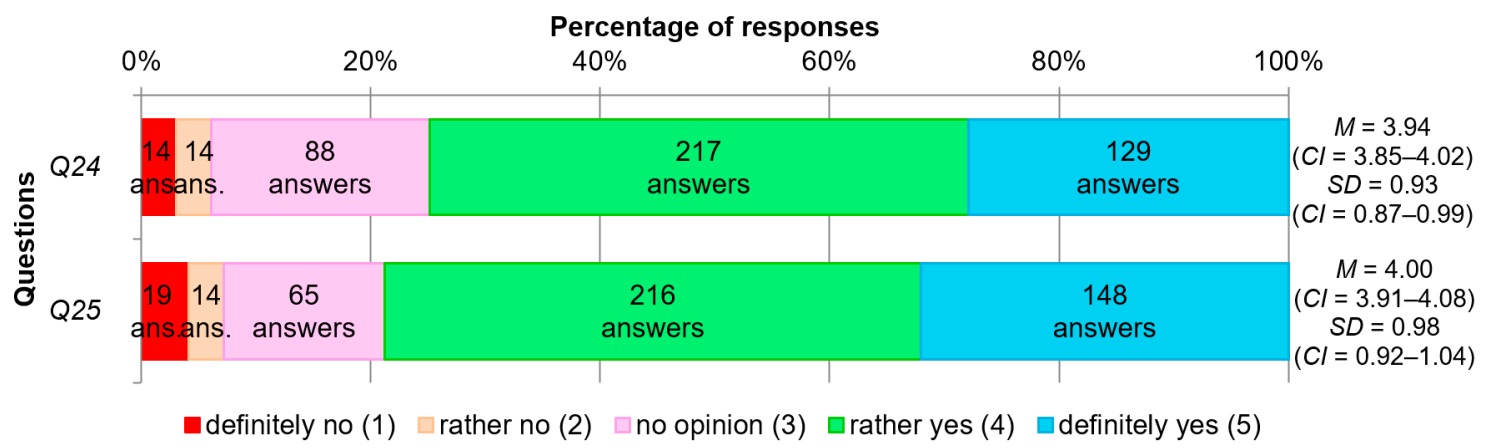

Figure 11. Assessment of legal factors influencing the choice of an alternative energy source for heating water in residential buildings $(M$-average, $S D$-standard deviation, $C I$-confidence interval, questions numbers $(Q)$ according to the Appendix A).

The factors presented in Figure 12 were also assessed relatively high. Almost 90\% of the respondents admitted that both the expected increase in the comfort of use of the installation $(Q 26)$ and hygiene issues $(Q 27)$ would have an impact on the choice of an alternative energy source for heating water. None of the respondents chose the answer "definitely no", and only $6 \%$ and $8 \%$ of the respondents chose the answer "rather no" for questions $Q 26$ and $Q 27$, respectively. While the use of shower heat exchangers will certainly not improve the protection of the installation against the growth of Legionella bacteria, reducing the temperature difference between the water supplied to the water heater and domestic hot water could improve the efficiency of this device. As a result, the comfort of using the installation would be improved, especially if the tankless hot water heater would be an energy source for a group of sanitary devices from which hot water could be drawn simultaneously.

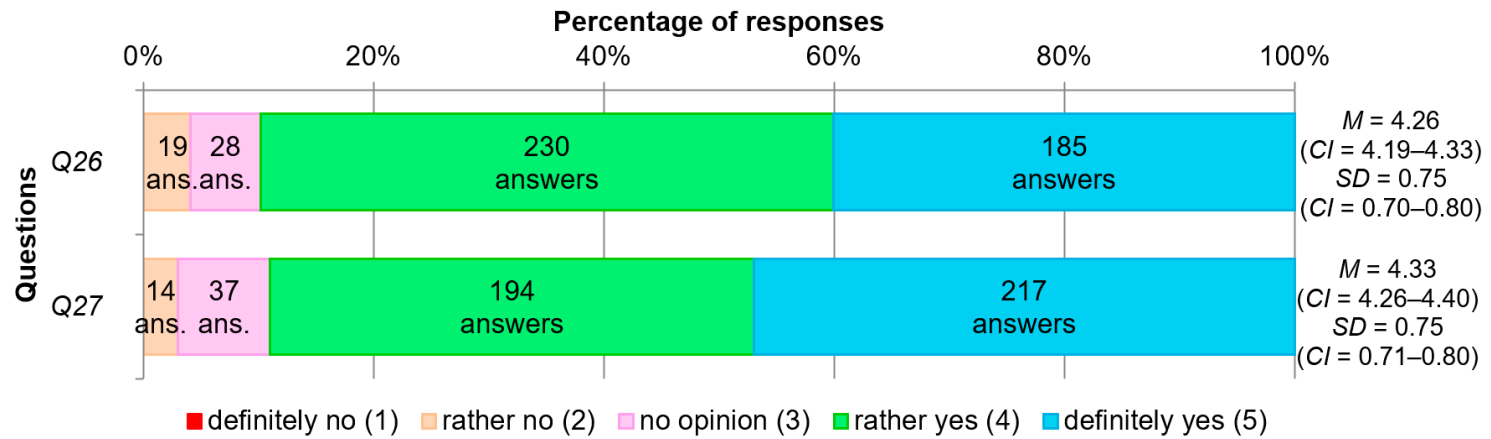

Figure 12. Assessment of social and hygienic factors influencing the choice of an alternative energy source for heating water in residential buildings ( $M$-average, $S D$ —standard deviation, $C I$-confidence interval; questions numbers $(Q)$ according to the Appendix A). 
In the opinion of the respondents, operational and technical issues also had a significant impact on the choice of an alternative energy source for heating water, as shown in Figure 13. In each case, the median of responses was $M e=4$. The highest average score $(M=4.33)$ was obtained by factors relating to the availability of information on individual systems $(Q 28)$ and the issue of the availability of a given energy source throughout the year (Q29). As already mentioned in Section 3.2, unlike second generation renewables (e.g., solar energy), energy from shower drain water is available all year round. The greatest amounts of energy can be recovered from greywater in winter, when the temperature of the cold tap water is the lowest. Then also the energy demand for heating water is the greatest. Greywater heat recovery systems are therefore characterized by a significant application potential, which currently remains unused. The reasons for this phenomenon are the lack of access to information on shower heat exchangers. This is important because in the case of question Q28, none of the respondents declared that access to information has no impact on the choice of an alternative energy source for hot water heating. Therefore, it can be expected that the continuation of the current approach of pro-ecological organizations and local authorities to the issue of wastewater heat recovery will constitute a significant barrier to their implementation in households and other buildings.

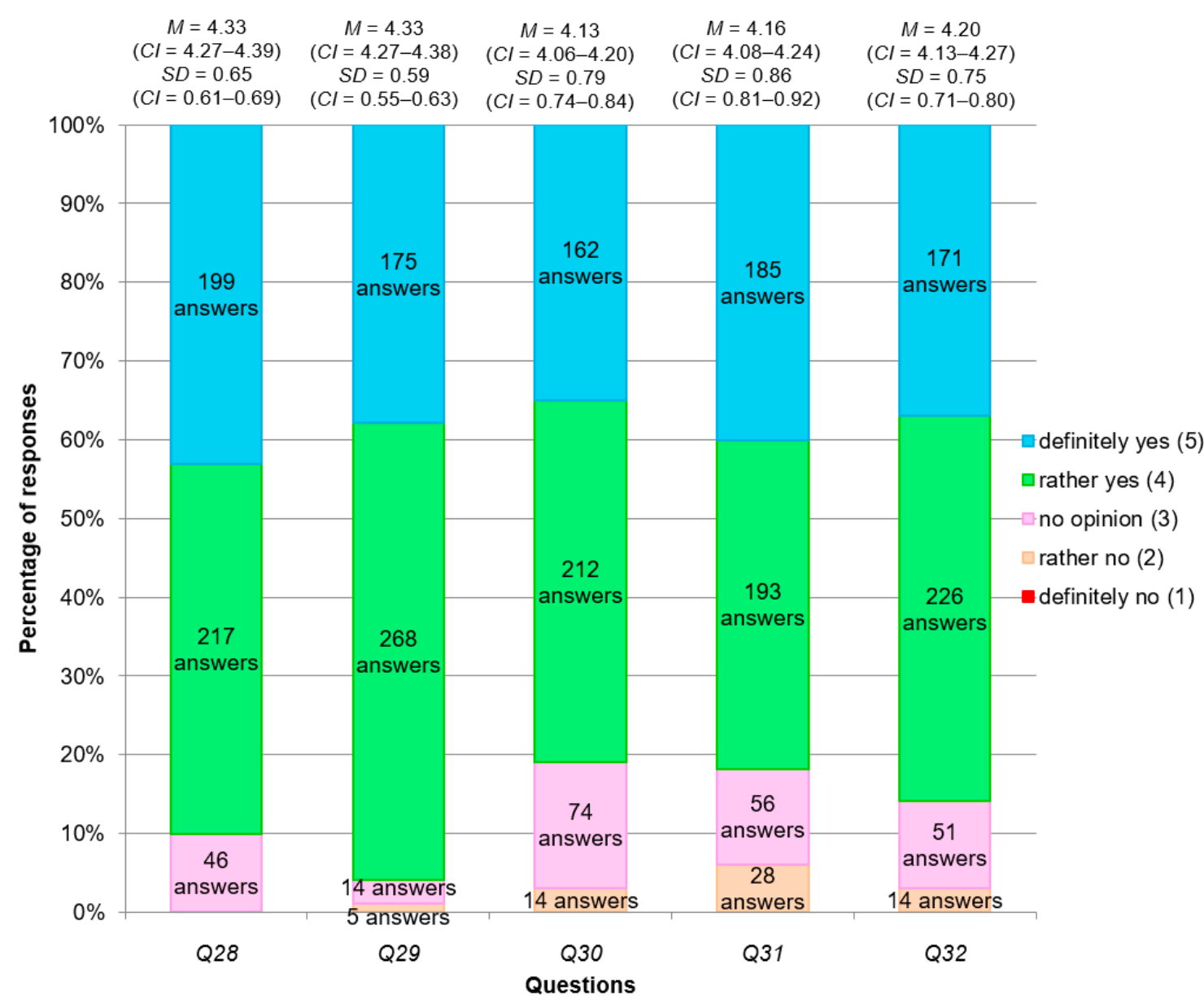

Figure 13. Assessment of operational and technical factors influencing the choice of an alternative energy source for heating water in residential buildings ( $M$-average, $S D$ —standard deviation, $C I$-confidence interval; questions numbers $(Q)$ according to the Appendix A).

A relatively high average score $(M=4.13-4.20)$ was also obtained by other questions, which were included in Figure 13. Over $80 \%$ of the respondents admitted that the possibility of using a given energy source together with other alternative energy sources would contribute to its use for heating water $(Q 30)$. This is also where the opportunity for 
wastewater heat recovery systems should be seen. There are examples of using drain water heat recovery units together with solar collectors [74]. These exchangers can also cooperate with a heat pump [75], and as is commonly known, heat pumps can collect energy from many sources.

A similar number of respondents admitted that when selecting an alternative energy source for water heating, they would take into account technical considerations related to the installation of the system $(Q 31)$. Considering that the installation of the shower heat exchanger in many cases requires a significant modification of the existing plumbing system, it should be assumed that greater application possibilities of these devices occur in newly built facilities. Only in 2020, over 200,000 dwellings were commissioned for use in Poland, of which approximately 10,000 in the Podkarpackie Voivodeship [76]. If shower heat exchangers were installed in every such building, it would save significant amounts of fossil fuels and reduce greenhouse gas emissions to the atmosphere. Research [77] shows that the use of a wastewater heat recovery system allows to reduce the emission of harmful substances by up to several dozen percent. Assuming that each such dwelling is inhabited by two people, the efficiency of the heat exchanger is $40 \%$, water consumption for showering is on average $35 \mathrm{~L}$ per person per day, cold, mixed and hot water temperatures are respectively $10{ }^{\circ} \mathrm{C}, 40^{\circ} \mathrm{C}$ and $55^{\circ} \mathrm{C}$, and the preheated water is supplied to both the hot water heater and the shower mixing valve, only in the Podkarpacie region it would be possible to save about 3.5 GWh of energy per year. The increase in the number of users of the shower installation and the use of heat exchangers with higher efficiency would result in an increase in the achieved energy savings. There are also other buildings from which large amounts of warm drain water are discharged, such as hotels or sports facilities.

The respondents also attached high importance to the factor regarding technical issues related to the use of the system, including the risk of scaling in water at a certain temperature $(Q 32)$. It should be noted that, as in the case of other factors included in Figure 13, the respondents were fairly consistent in their responses. Only $3 \%$ admitted that these issues would not matter to them, and none of them chose the answer "definitely no". In the case of shower heat exchangers, however, the risk of scaling is negligible, as the preheated water usually does not reach a hazardous temperature in this regard.

\subsection{The Use of Shower Heat Exchangers}

The last part of the survey concerned the use of shower heat exchangers. The respondents were asked about the amount and temperature of water used for showering, the characteristics of the plumbing system in the building they live in, as well as their opinion on the heat exchangers under consideration. The results are summarized in Figure 14.

The research has shown that nearly $70 \%$ of the respondents have never heard of shower heat exchangers (Q33). It is worth emphasizing that almost $80 \%$ of them chose the answer "definitely no". A significant part of the survey participants (17.5\%) did not have an opinion on this subject, and only less than $14 \%$ admitted that they were familiar with these devices. These results should be considered very unfavorable from the point of view of implementing shower heat exchangers. In the previous part of the survey (Q28), the respondents indicated that the availability of information on individual systems has a significant impact on the choice of an alternative energy source for heating water. In the case of shower heat exchangers, it turned out that not only is there a lack of wide access to information about these devices, but the greater part of the society is not aware of their existence and the possibilities that their application brings. This is also confirmed by the answers to the questions about the price $(Q 40)$ and efficiency $(Q 41)$ of shower heat exchangers, as the majority of the respondents (over $80 \%$ ) were not able to comment on this topic. An additional barrier to the implementation of shower heat exchangers may also be the fear of using the heat deposited in greywater (Q34). Over $45 \%$ of the respondents admitted that they have concerns about the use of shower heat recovery systems. About $20 \%$ chose the "no opinion" option, and only 10\% said that heat recovery from shower drain water would definitely not be a problem for them. 


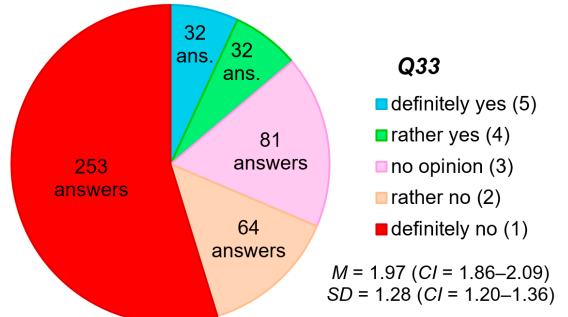

(a)

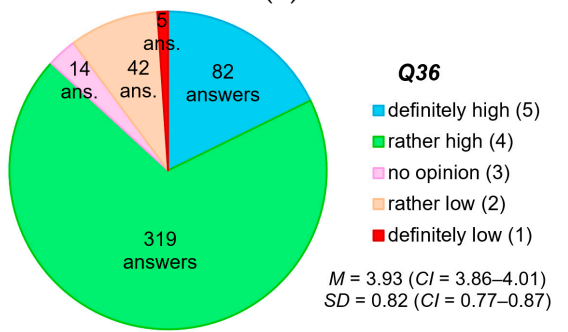

(d)

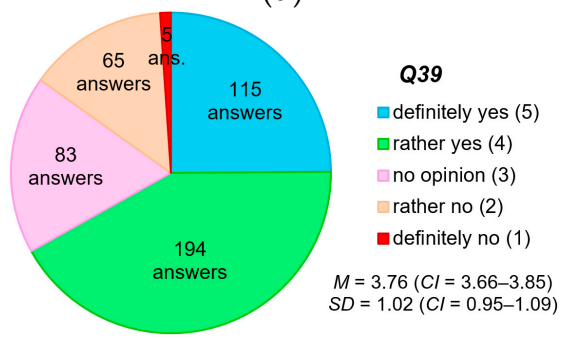

(g)

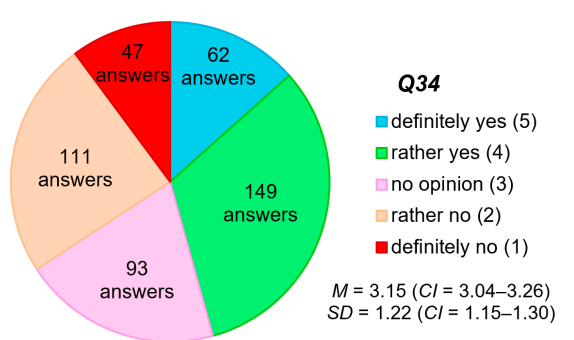

(b)

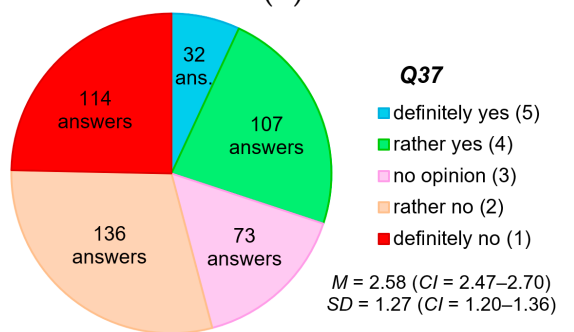

(e)

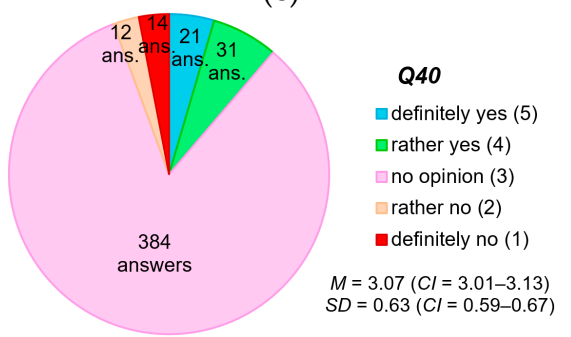

(h)

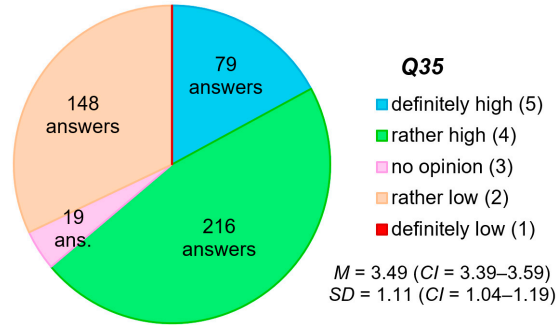

(c)

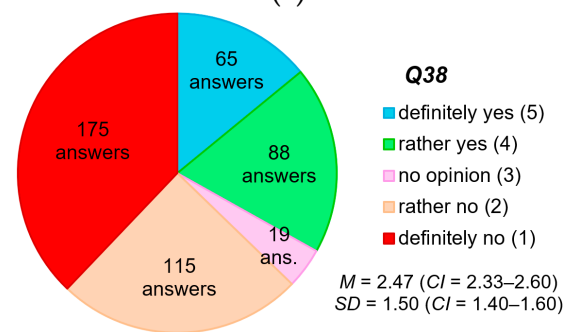

(f)

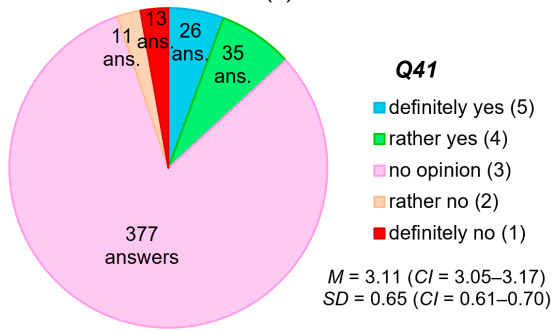

(i)

Figure 14. Assessment of the possibility of implementing shower heat exchangers in residential buildings ( $M$-average, $S D$ —standard deviation, $C I$ —confidence interval; questions numbers $(Q)$ according to the Appendix A): (a) question Q33; (b) question $Q 34 ;$ (c) question $Q 35 ;(\mathbf{d})$ question $Q 36 ;(\mathbf{e})$ question $Q 37 ;$ (f) question Q38; (g) question Q39; (h) question Q40; (i) question $Q 41$.

In the case of existing buildings, the method of conducting internal plumbing should also be considered. This is important not only from the point of view of the selection of an appropriate mounting method for the shower heat exchanger and its type, but also due to the need to accurately estimate the installation costs. The research showed that only about $30 \%$ of the respondents have space in their dwellings to install a vertical heat exchanger, with the answer "definitely yes" indicated by only $23 \%$ of them (Q37). As is well known, it is these devices that are most effective and are most often used [61]. The use of devices with a different design results in a reduction of the amount of recovered heat. Therefore, it is necessary to look for new heat exchanger solutions that can be installed under the floor linear shower drain or on the horizontal shower waste pipe, and the efficiency of which will be satisfactory. Additionally, almost $63 \%$ of the respondents admitted that in their households the device for heating domestic hot water is located at a considerable distance from the shower $(Q 38)$. In such a situation, the only reasonable solution seems to be to supply the preheated water only to the shower mixing valve instead of the cold water. Considering that this method of installation is most often used when horizontal heat exchangers and devices installed under the floor shower drain are used, it confirms the need to look for more effective solutions in this group of devices. Especially since only $15 \%$ of the respondents admitted that installing a shower heat exchanger in their dwellings would not require significant modifications to the existing plumbing (Q39).

The results described above are very unfavorable from the point of view of the implementation of shower heat exchangers, especially since the vast majority of the respondents assessed the water consumption for showering $(Q 35)$ and the temperature of the water used for this purpose $(Q 36)$ as high. It is obvious that the greater the amount and temperature 
of water used, the more energy can be recovered and the greater the financial savings associated with it. The use of these devices on a global scale would also contribute to counteracting climate change by reducing emissions of $\mathrm{CO}_{2}$ and other products of fuel combustion. However, in many cases, despite the possibility of significantly reducing the unit costs of heating water, the application of shower heat exchangers may turn out to be technically and financially unjustified due to the unfavorable arrangement of internal installations in the building.

The last two questions of the survey concerned the assessment of interest in the use of shower heat exchangers, with $Q 42$ relating to existing buildings and $Q 43$ to new facilities. Based on the answers (Figure 15), it can be concluded that the interest in using these devices in existing residential buildings is low. Less than $7 \%$ of the respondents answered "definitely yes". Only 36 more people selected the "rather yes" option. The largest number of people participating in the survey $(46.5 \%)$ admitted that they had no opinion on this subject, which confirms the lack of public awareness of the use of shower heat exchangers. Over $27 \%$ of the respondents stated that they are not interested in using these devices in their homes, which probably results from the necessity to significantly modify the plumbing system. The situation is a bit better in the case of newly built facilities (Q43). More than half of the respondents declared that they would consider using such a device when building a house. However, almost $30 \%$ of people taking part in the survey do not have an opinion on this subject, and $17 \%$ admit that they will not use the shower heat exchanger even in a new building. It should also be considered that the interest in using a given device is not tantamount to its installation in the building. The barrier may be the high price of the heat exchanger, its low efficiency or the lack of availability of solutions on the Polish market that will meet the expectations of the potential users. This confirms the need to promote the idea of wastewater heat recovery and to develop new, highly efficient designs of shower heat exchangers.

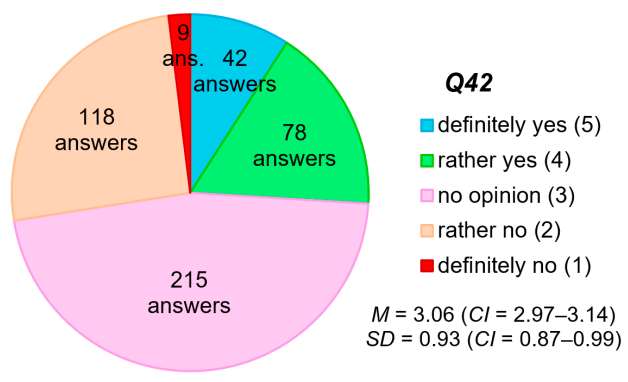

(a)

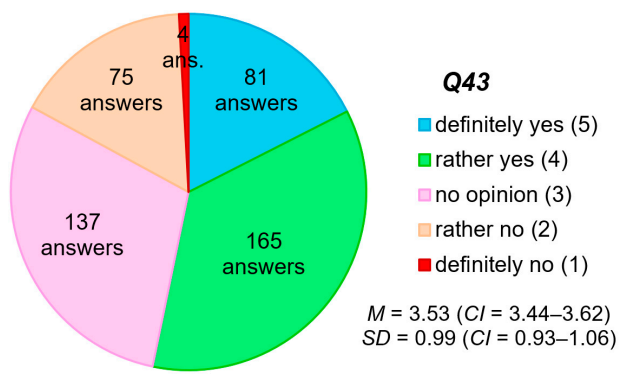

(b)

Figure 15. Assessment of interest in the use of shower heat exchangers ( $M$-average, $S D$-standard deviation, $C I-$ confidence interval; questions numbers (Q) according to the Appendix A): (a) question Q42; (b) question Q43.

\subsection{Analysis of the Associations}

As part of the research, the associations between the respondents' answers to individual questions were also analyzed. This analysis was based on Cramér's $V$ coefficients. The calculation results are presented in Appendix B due to the large amount of data (over 1800 comparisons). In Tables A2-A4 those results which indicate a high association between the answers to the questions are marked in red. Blue is a moderate association and green is a low association.

The presented results prove that the minimum threshold suggesting the existence of the association between the answers to two questions was exceeded in most cases. However, it should be noted that many of these values only slightly exceed 0.1 , indicating the presence of a low association. Stronger links can only be observed in a few cases. High and moderate associations were observed, for example, in relation to questions concerning the impact of economic issues on the choice of an alternative energy source for water heating $(Q 19-Q 23)$. In the case of the question about the cost of purchasing and installing a 
device (Q19), there is also a link with questions about the availability of information on a given energy source $(Q 28)$, its availability throughout the year $(Q 29)$ and the possibility of using it with other energy sources (Q30).

The analysis also showed that the preferences of the respondents regarding the influence of technical issues on saving energy for heating water (Q16) are closely related to their opinion on the influence of these factors on the choice of alternative energy sources (Q31 and Q32). A similar tendency was observed in the case of legal (Q14 vs. Q24 and $Q 25)$ and social issues ( $Q 15$ vs. $Q 26$ and $Q 27)$. This association is noticeable, although slightly smaller, also in relation to environmental factors (Q12 vs. Q17 and Q18). However, no significant associations were noted between the assessment of the impact of economic benefits on the decision to save energy $(Q 13)$ and the impact of economic issues on the choice of an alternative energy source.

In the last part of the survey, concerning the use of shower heat exchangers, there is a clear correlation between the answers to questions $Q 42$ and $Q 43$. People who show interest in the application of a shower heat exchanger in an existing apartment building will also be interested in this type of investment in the future. In the case of the remaining questions that were included in this part of the questionnaire, the associations are not so clear. The moderate associations can be noticed between the answers to the question about the knowledge of shower heat exchangers $(Q 33)$ and the answers to the questions $Q 40-Q 43$. This is probably due to the fact that people who did not have sufficient knowledge on the use of shower heat exchangers were not able to assess them.

It is also important that the survey research did not show any significant associations between the demographic characteristics of the respondents and their opinion on the impact of the studied factors on the decision to save energy for water heating and the choice of an alternative energy source. There is also no noticeable relationship between the age, gender or level of education of people participating in the survey and their preferences regarding the use of shower heat exchangers. For this reason, these devices have a significant application potential among all social groups. Only this potential should be properly used.

\section{Conclusions}

The research identified factors determining energy saving for heating water in residential buildings and choosing an alternative energy source. The possibilities of using shower heat exchangers were also assessed, as well as the willingness of the society to use this type of devices in residential buildings. Based on the results of the survey, it can be concluded that the perspective of protecting the natural environment and its resources is not a sufficient argument to encourage users to save energy for heating water. It is necessary to introduce appropriate incentives and motivators that would induce society to care for the state of the environment and climate of our planet, as well as universal pro-environmental education.

The analysis showed that the main barrier to the implementation of shower heat exchangers in the Podkarpackie Voivodeship is the lack of access to information on these devices. A significant part of the society is not familiar with this solution and is not aware of the possibilities that its use brings. It is therefore necessary to introduce programs promoting the use of these devices. An equally important issue is ensuring an appropriate source of financing for the purchase of shower heat exchangers. The impact of financial issues on the decision to save energy is admittedly less significant than other factors, however, in the case of choosing an alternative energy source, it plays an important role. Considering that the price of shower heat exchangers is in many cases inadequate to the financial savings achieved, the search for new, highly efficient heat exchanger designs remains an important issue. The devices installed under the floor shower drain and on the horizontal shower waste pipe have the greatest potential. In their case, the preheated water is usually fed only to the shower mixing valve. This limits the scope of the required installation works, thus making it possible to use the device in an existing building, and 
makes the system operation independent of the type of heat source. The possibilities of using vertical heat exchangers in most cases are limited to newly built facilities due to technical problems that could occur in existing buildings.

The analysis of associations also showed that demographic issues do not have a significant impact on the preferences of respondents regarding the use of shower heat exchangers. For this reason, these devices have a significant application potential among all social groups. Only this potential should be properly used.

The role played by the legislator should not be forgotten either. The introduction of relevant legal regulations requiring the use of greywater as an alternative energy source would certainly contribute to the increased interest in shower heat exchangers.

The research was conducted among the inhabitants of only one voivodeship, which is certainly their limitation. Further research will therefore focus on people living also in other parts of the country. This will allow not only to identify the differences in the approach to energy saving in different parts of Poland, but also indirectly to characterize the differentiation of the socio-economic development of voivodeships. Collecting a wider set of data will also identify those factors that have the greatest impact on the level of interest in the use of shower heat exchangers, which will be possible thanks to the use of advanced statistical tools.

The conducted survey research also showed that the number of potential recipients of horizontal heat exchangers is much greater than that of devices with vertical flow. The problem, however, is the insufficient efficiency of such devices. For this reason, further research will focus on developing innovative, highly efficient solutions for heat exchangers installed under the floor linear shower drain or on the horizontal shower waste pipe.

Author Contributions: Conceptualization, S.K.-O. and M.S.; methodology, S.K.-O. and M.S; software, S.K.-O. and M.S.; validation, S.K.-O. and M.S.; formal analysis, S.K.-O. and M.S.; data curation, S.K.O. and M.S.; writing-original draft preparation, S.K.-O.; writing—review and editing, S.K.-O.; visualization, S.K.-O.; supervision, D.S. All authors have read and agreed to the published version of the manuscript.

Funding: This research received no external funding.

Institutional Review Board Statement: Not applicable.

Informed Consent Statement: Not applicable.

Data Availability Statement: Not applicable.

Acknowledgments: The authors would like to thank all those who responded to the survey.

Conflicts of Interest: The authors declare no conflict of interest.

\section{Appendix A}

Table A1 lists the questions that were included in the questionnaire.

Table A1. List of questions included in the survey (translated from polish).

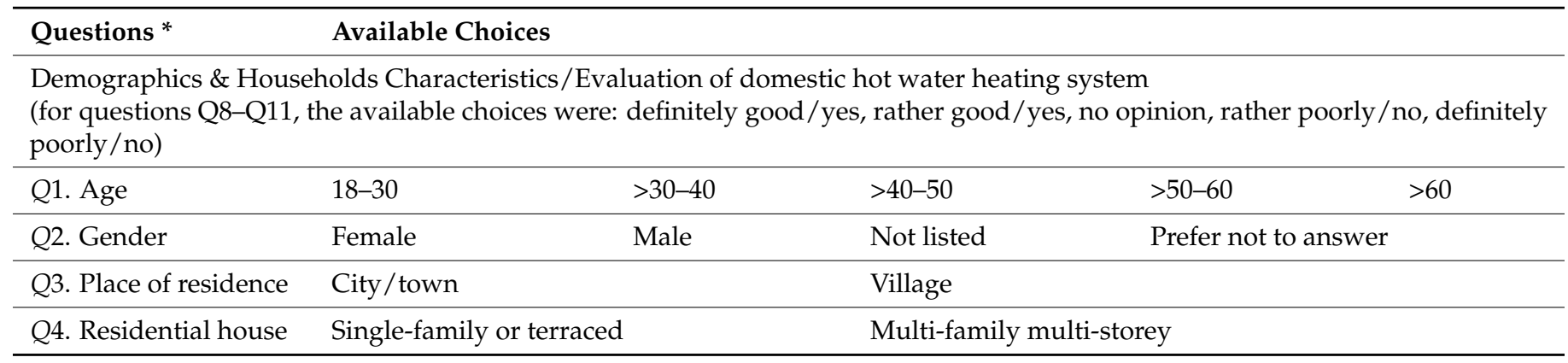


Table A1. Cont.

\begin{tabular}{|c|c|c|c|c|}
\hline Questions* & \multicolumn{4}{|l|}{ Available Choices } \\
\hline Q5. Education & Master's degree & $\begin{array}{l}\text { Bachelor's } \\
\text { degree }\end{array}$ & High school & Professional certification \\
\hline $\begin{array}{l}\text { Q6. The main source } \\
\text { of domestic hot water }\end{array}$ & $\begin{array}{l}\text { District heating system } \\
\text { Solid fuel boiler }\end{array}$ & Gas water heater & $\begin{array}{l}\text { Electric water heater } \\
\text { Other }\end{array}$ & Gas boiler \\
\hline \multirow{2}{*}{$\begin{array}{l}\text { Q7. Additional device } \\
\text { for heating water }\end{array}$} & Solar panels & Heat pump & Biomass boiler & Shower heat exchanger \\
\hline & \multicolumn{2}{|c|}{ Device that uses fossil energy sources } & \multicolumn{2}{|c|}{ Other renewable energy source device } \\
\hline \multicolumn{5}{|c|}{ Q8. How do you rate your domestic hot water heating system? } \\
\hline \multicolumn{5}{|c|}{ Q9. Are your energy bills for heating water acceptable? } \\
\hline \multicolumn{5}{|c|}{ Q10. Do you experience any inconvenience with your domestic hot water heating system? } \\
\hline
\end{tabular}

Factors determining energy saving for water heating

(for questions $Q 12-Q 16$, the available choices were: definitely yes, rather yes, no opinion, rather no, definitely no)

Q12. Would the possibility of protecting the environment and natural resources induce you to save energy for heating water?

Q13. Would the possibility of achieving economic benefits induce you to save energy for heating water?

Q14. Would the introduction of legal regulations imposing energy saving and emission reduction induce you to save energy for water heating?

Q15. Would the possible increase in the comfort and safety of installation use encourage you to save energy for heating water?

Q16. Could technical facilitations related to the installation and operation of the system as well as the availability of energy sources encourage you to save energy for heating water?

Factors influencing the choice of an alternative energy source

(for questions $Q 17-Q 32$, the available choices were: definitely yes, rather yes, no opinion, rather no, definitely no)

Q17. Would the amount of GHG reduction resulting from the use of an alternative energy source for heating water affect its choice?

Q18. Would the amount of potentially saved energy resources affect the choice of an alternative energy source for heating water?

Q19. Would the cost of purchasing and installing individual devices affect the choice of an alternative energy source for heating water?

Q20. Would the unit cost of heating water affect the choice of an alternative energy source for heating water?

Q21. Would the costs of maintenance and possible repair of the system affect the choice of an alternative energy source for heating water?

Q22. Would the expected service life of the system affect the choice of an alternative energy source for heating water?

Q23. Would the possibility of obtaining financing for the purchase of the system affect the choice of an alternative energy source for heating water?

Q24. Would the introduction of legal regulations requiring the use of specific energy sources affect their choice as an alternative energy source for water heating?

Q25. Would the introduction of legal regulations ordering the reduction of greenhouse gas emissions resulting from the combustion of fuels affect the choice of an alternative energy source for water heating?

Q26. Would the expected increase in the level of comfort of use of the hot water system affect the choice of an alternative energy source for heating water?

Q27. Would hygiene considerations, including prevention of Legionella bacteria growth, affect the choice of an alternative energy source for heating water?

Q28. Would the availability of information on individual systems affect the choice of an alternative energy source for heating water?

Q29. Would issues related to the availability of a given energy source throughout the year affect its choice as an alternative energy source for heating water?

Q30. Would the possibility of using a given energy source together with other alternative energy sources for heating water affect its choice? 
Table A1. Cont.

Questions * Available Choices

Q31. Would technical considerations related to the installation of the system, including the need to modify the plumbing, affect the choice of an alternative energy source for water heating?

Q32. Would technical considerations related to the operation of the system, including the risk of scaling in water at a certain temperature, affect the choice of an alternative energy source for heating water?

The use of shower heat exchangers

(for questions Q33-Q43, the available choices were: definitely yes/high, rather yes/high, no opinion, rather no/low, definitely no/low)

Q33. Have you ever heard of shower heat exchangers?

Q34. Are you afraid of using the energy deposited in drain water?

Q35. How would you rate the water consumption for showering in your home?

Q36. How would you rate the temperature of the mixed water used for showering in your home?

Q37. Do you have space to install a vertical DWHR heat exchanger below the shower drain?

Q38. Is there a water heating device in your home close to the shower?

Q39. Would installing a shower heat exchanger in your apartment require significant modifications to the existing plumbing?

Q40. Is the price of shower heat exchangers available on the market acceptable to you?

Q41. Is the efficiency of shower heat exchangers available on the market acceptable to you?

Q42. Are you interested in using a drain water heat recovery system in your existing apartment?

Q43. Are you interested in using a drain water heat recovery system in the construction of a new house?

* Available online: https://docs.google.com/forms/d/e/1FAIpQLSeKVely1biIH6_1mGHFxgvTjfMVFtjTOmGHILew2LkzVwosjQ/ viewform (accessed on 16 July 2021).

\section{Appendix B}

Tables A2-A4 shows the values of the Cramér's $V$ coefficient.

Table A2. The values of the Cramer's V coefficient for questions $Q 1-Q 15$ (questions numbers $(Q)$ according to the Appendix A).

\begin{tabular}{|c|c|c|c|c|c|c|c|c|c|c|c|c|c|c|c|}
\hline & $Q 1$ & $Q^{2}$ & $Q 3$ & $Q 4$ & Q5 & Q6 & $Q 7$ & $Q 7$ & $Q 8$ & $Q 10$ & $Q 11$ & $Q 12$ & $Q 13$ & $Q 14$ & $Q 15$ \\
\hline$Q 1$ & 1.00 & 0.09 & 0.01 & 0.37 & 0.19 & 0.48 & 0.34 & 0.16 & 0.24 & 0.15 & 0.15 & 0.12 & 0.13 & 0.07 & 0.11 \\
\hline$\widetilde{Q} 2$ & 0.09 & 1.00 & 0.05 & 0.02 & 0.09 & 0.05 & 0.11 & 0.06 & 0.10 & 0.09 & 0.07 & 0.14 & 0.08 & 0.05 & 0.06 \\
\hline$Q 3$ & 0.01 & 0.05 & - & - & 0.11 & 0.54 & 0.26 & 0.04 & 0.29 & 0.16 & 0.23 & 0.07 & 0.11 & 0.06 & 0.12 \\
\hline$\widetilde{Q} 4$ & 0.37 & 0.02 & - & - & 0.10 & 0.85 & 0.58 & 0.08 & 0.41 & 0.30 & 0.42 & 0.16 & 0.06 & 0.09 & 0.11 \\
\hline Q5 & 0.19 & 0.09 & 0.11 & 0.10 & 1.00 & 0.09 & 0.12 & 0.08 & 0.09 & 0.10 & 0.06 & 0.10 & 0.10 & 0.08 & 0.09 \\
\hline Q6 & 0.48 & 0.05 & 0.54 & 0.85 & 0.09 & 1.00 & 0.33 & 0.18 & 0.35 & 0.20 & 0.33 & 0.16 & 0.09 & 0.11 & 0.09 \\
\hline$\widetilde{Q} 7$ & 0.34 & 0.11 & 0.26 & 0.58 & 0.12 & 0.33 & 1.00 & 0.11 & 0.27 & 0.14 & 0.14 & 0.08 & 0.12 & 0.08 & 0.12 \\
\hline Q8 & 0.16 & 0.06 & 0.04 & 0.08 & 0.08 & 0.18 & 0.11 & 1.00 & 0.18 & 0.49 & 0.11 & 0.09 & 0.10 & 0.05 & 0.05 \\
\hline$\tilde{Q}^{9}$ & 0.24 & 0.10 & 0.29 & 0.41 & 0.09 & 0.35 & 0.27 & 0.18 & 1.00 & 0.13 & 0.18 & 0.10 & 0.06 & 0.08 & 0.12 \\
\hline$Q 10$ & 0.15 & 0.09 & 0.16 & 0.30 & 0.10 & 0.20 & 0.14 & 0.49 & 0.13 & 1.00 & 0.11 & 0.11 & 0.11 & 0.08 & 0.06 \\
\hline Q11 & 0.15 & 0.07 & 0.23 & 0.42 & 0.06 & 0.33 & 0.14 & 0.11 & 0.18 & 0.11 & 1.00 & 0.31 & 0.12 & 0.09 & 0.15 \\
\hline Q12 & 0.12 & 0.14 & 0.07 & 0.16 & 0.10 & 0.16 & 0.08 & 0.09 & 0.10 & 0.11 & 0.31 & 1.00 & 0.16 & 0.23 & 0.20 \\
\hline$Q 13$ & 0.13 & 0.08 & 0.11 & 0.06 & 0.10 & 0.09 & 0.12 & 0.10 & 0.06 & 0.11 & 0.12 & 0.16 & 1.00 & 0.11 & 0.15 \\
\hline Q14 & 0.07 & 0.05 & 0.06 & 0.09 & 0.08 & 0.11 & 0.08 & 0.05 & 0.08 & 0.08 & 0.09 & 0.23 & 0.11 & 1.00 & 0.12 \\
\hline Q15 & 0.11 & 0.06 & 0.12 & 0.11 & 0.09 & 0.09 & 0.12 & 0.05 & 0.12 & 0.06 & 0.15 & 0.20 & 0.15 & 0.12 & 1.00 \\
\hline$\widetilde{Q} 16$ & 0.08 & 0.06 & 0.02 & 0.09 & 0.08 & 0.07 & 0.12 & 0.18 & 0.07 & 0.17 & 0.08 & 0.12 & 0.11 & 0.17 & 0.08 \\
\hline$\widetilde{Q} 17$ & 0.12 & 0.12 & 0.07 & 0.09 & 0.09 & 0.11 & 0.09 & 0.08 & 0.09 & 0.06 & 0.22 & 0.39 & 0.12 & 0.14 & 0.14 \\
\hline$\widetilde{Q} 18$ & 0.13 & 0.10 & 0.10 & 0.07 & 0.08 & 0.10 & 0.07 & 0.08 & 0.08 & 0.08 & 0.21 & 0.36 & 0.12 & 0.10 & 0.12 \\
\hline Q19 & 0.09 & 0.08 & 0.12 & 0.15 & 0.09 & 0.12 & 0.11 & 0.10 & 0.09 & 0.10 & 0.10 & 0.13 & 0.11 & 0.10 & 0.05 \\
\hline
\end{tabular}


Table A2. Cont.

\begin{tabular}{|c|c|c|c|c|c|c|c|c|c|c|c|c|c|c|c|}
\hline & $Q 1$ & $Q 2$ & $Q^{3}$ & $Q 4$ & Q5 & Q6 & $Q 7$ & $Q 7$ & $Q 8$ & $Q 10$ & $Q 11$ & $Q 12$ & $Q 13$ & $Q 14$ & $Q 15$ \\
\hline$Q 20$ & 0.11 & 0.09 & 0.10 & 0.11 & 0.08 & 0.15 & 0.12 & 0.07 & 0.10 & 0.11 & 0.11 & 0.14 & 0.09 & 0.11 & 0.06 \\
\hline Q21 & 0.22 & 0.06 & 0.09 & 0.11 & 0.09 & 0.30 & 0.13 & 0.11 & 0.18 & 0.10 & 0.17 & 0.18 & 0.14 & 0.09 & 0.07 \\
\hline$\tilde{Q} 22$ & 0.12 & 0.07 & 0.07 & 0.11 & 0.05 & 0.17 & 0.13 & 0.09 & 0.12 & 0.10 & 0.12 & 0.10 & 0.13 & 0.11 & 0.07 \\
\hline Q23 & 0.09 & 0.07 & 0.17 & 0.24 & 0.11 & 0.18 & 0.15 & 0.07 & 0.14 & 0.11 & 0.15 & 0.18 & 0.09 & 0.09 & 0.06 \\
\hline$\widetilde{Q} 24$ & 0.10 & 0.08 & 0.09 & 0.14 & 0.08 & 0.14 & 0.08 & 0.07 & 0.10 & 0.09 & 0.10 & 0.21 & 0.10 & 0.75 & 0.14 \\
\hline Q25 & 0.10 & 0.07 & 0.11 & 0.10 & 0.09 & 0.14 & 0.08 & 0.08 & 0.11 & 0.08 & 0.11 & 0.20 & 0.11 & 0.65 & 0.16 \\
\hline Q26 & 0.11 & 0.07 & 0.10 & 0.10 & 0.09 & 0.11 & 0.14 & 0.05 & 0.12 & 0.08 & 0.10 & 0.16 & 0.15 & 0.21 & 0.70 \\
\hline$\stackrel{Q}{27}$ & 0.11 & 0.06 & 0.11 & 0.10 & 0.07 & 0.09 & 0.13 & 0.05 & 0.11 & 0.06 & 0.11 & 0.17 & 0.15 & 0.15 & 0.73 \\
\hline$\widetilde{Q} 28$ & 0.09 & 0.08 & 0.07 & 0.10 & 0.08 & 0.10 & 0.13 & 0.09 & 0.08 & 0.12 & 0.09 & 0.19 & 0.05 & 0.17 & 0.16 \\
\hline $\mathcal{Q}^{29}$ & 0.08 & 0.09 & 0.10 & 0.15 & 0.08 & 0.11 & 0.09 & 0.09 & 0.09 & 0.08 & 0.10 & 0.13 & 0.06 & 0.13 & 0.18 \\
\hline Q30 & 0.11 & 0.06 & 0.09 & 0.13 & 0.08 & 0.14 & 0.11 & 0.10 & 0.10 & 0.06 & 0.13 & 0.13 & 0.05 & 0.18 & 0.23 \\
\hline$\widetilde{Q} 31$ & 0.09 & 0.06 & 0.08 & 0.11 & 0.07 & 0.10 & 0.14 & 0.18 & 0.06 & 0.16 & 0.07 & 0.07 & 0.11 & 0.15 & 0.08 \\
\hline Q32 & 0.11 & 0.06 & 0.07 & 0.07 & 0.07 & 0.12 & 0.10 & 0.17 & 0.04 & 0.16 & 0.06 & 0.10 & 0.12 & 0.14 & 0.11 \\
\hline$\widetilde{Q} 33$ & 0.16 & 0.06 & 0.06 & 0.17 & 0.13 & 0.16 & 0.19 & 0.09 & 0.10 & 0.10 & 0.10 & 0.12 & 0.11 & 0.08 & 0.09 \\
\hline$\widetilde{Q} 34$ & 0.09 & 0.08 & 0.04 & 0.05 & 0.10 & 0.12 & 0.09 & 0.11 & 0.10 & 0.09 & 0.10 & 0.11 & 0.10 & 0.06 & 0.10 \\
\hline Q35 & 0.09 & 0.06 & 0.14 & 0.20 & 0.08 & 0.16 & 0.10 & 0.05 & 0.12 & 0.09 & 0.13 & 0.08 & 0.10 & 0.10 & 0.10 \\
\hline Q36 & 0.14 & 0.10 & 0.11 & 0.04 & 0.06 & 0.12 & 0.09 & 0.11 & 0.09 & 0.09 & 0.09 & 0.10 & 0.08 & 0.10 & 0.09 \\
\hline Q37 & 0.17 & 0.13 & 0.15 & 0.11 & 0.11 & 0.14 & 0.11 & 0.12 & 0.07 & 0.11 & 0.08 & 0.07 & 0.08 & 0.11 & 0.08 \\
\hline$\widetilde{Q} 38$ & 0.23 & 0.06 & 0.23 & 0.21 & 0.08 & 0.16 & 0.09 & 0.09 & 0.13 & 0.10 & 0.11 & 0.10 & 0.10 & 0.08 & 0.09 \\
\hline Q39 & 0.11 & 0.08 & 0.11 & 0.07 & 0.08 & 0.11 & 0.08 & 0.07 & 0.12 & 0.07 & 0.11 & 0.13 & 0.10 & 0.09 & 0.09 \\
\hline$Q 40$ & 0.09 & 0.08 & 0.09 & 0.08 & 0.10 & 0.11 & 0.11 & 0.13 & 0.13 & 0.08 & 0.08 & 0.08 & 0.11 & 0.07 & 0.07 \\
\hline$\widetilde{Q} 41$ & 0.12 & 0.06 & 0.06 & 0.12 & 0.08 & 0.13 & 0.16 & 0.10 & 0.11 & 0.08 & 0.09 & 0.10 & 0.10 & 0.09 & 0.08 \\
\hline$\widetilde{Q} 42$ & 0.14 & 0.06 & 0.20 & 0.21 & 0.11 & 0.16 & 0.18 & 0.11 & 0.16 & 0.12 & 0.10 & 0.09 & 0.08 & 0.09 & 0.13 \\
\hline Q43 & 0.12 & 0.08 & 0.23 & 0.24 & 0.07 & 0.14 & 0.11 & 0.09 & 0.15 & 0.12 & 0.10 & 0.09 & 0.12 & 0.10 & 0.10 \\
\hline
\end{tabular}

Table A3. The values of the Cramer's V coefficient for questions $Q 16-Q 30$ (questions numbers $(Q)$ according to the Appendix A).

\begin{tabular}{|c|c|c|c|c|c|c|c|c|c|c|c|c|c|c|c|}
\hline & $Q 16$ & $Q 17$ & $Q 18$ & $Q 19$ & $Q 20$ & $Q 21$ & $Q 22$ & $Q 23$ & $Q 24$ & Q25 & $Q 26$ & $Q 27$ & $Q 28$ & $Q 29$ & $Q 30$ \\
\hline$Q 1$ & 0.08 & 0.12 & 0.13 & 0.09 & 0.11 & 0.22 & 0.12 & 0.09 & 0.10 & 0.10 & 0.11 & 0.11 & 0.09 & 0.08 & 0.11 \\
\hline Q2 & 0.06 & 0.12 & 0.10 & 0.08 & 0.09 & 0.06 & 0.07 & 0.07 & 0.08 & 0.07 & 0.07 & 0.06 & 0.08 & 0.09 & 0.06 \\
\hline$Q 3$ & 0.02 & 0.07 & 0.10 & 0.12 & 0.10 & 0.09 & 0.07 & 0.17 & 0.09 & 0.11 & 0.10 & 0.11 & 0.07 & 0.10 & 0.09 \\
\hline$\widetilde{Q} 4$ & 0.09 & 0.09 & 0.07 & 0.15 & 0.11 & 0.11 & 0.11 & 0.24 & 0.14 & 0.10 & 0.10 & 0.10 & 0.10 & 0.15 & 0.13 \\
\hline$\widetilde{Q} 5$ & 0.08 & 0.09 & 0.08 & 0.09 & 0.08 & 0.09 & 0.05 & 0.11 & 0.08 & 0.09 & 0.09 & 0.07 & 0.08 & 0.08 & 0.08 \\
\hline Q6 & 0.07 & 0.11 & 0.10 & 0.12 & 0.15 & 0.30 & 0.17 & 0.18 & 0.14 & 0.14 & 0.11 & 0.09 & 0.10 & 0.11 & 0.14 \\
\hline$\widetilde{Q} 7$ & 0.12 & 0.09 & 0.07 & 0.11 & 0.12 & 0.13 & 0.13 & 0.15 & 0.08 & 0.08 & 0.14 & 0.13 & 0.13 & 0.09 & 0.11 \\
\hline Q8 & 0.18 & 0.08 & 0.08 & 0.10 & 0.07 & 0.11 & 0.09 & 0.07 & 0.07 & 0.08 & 0.05 & 0.05 & 0.09 & 0.09 & 0.10 \\
\hline$\tilde{Q}^{9}$ & 0.07 & 0.09 & 0.08 & 0.09 & 0.10 & 0.18 & 0.12 & 0.14 & 0.10 & 0.11 & 0.12 & 0.11 & 0.08 & 0.09 & 0.10 \\
\hline$Q 10$ & 0.17 & 0.06 & 0.08 & 0.10 & 0.11 & 0.10 & 0.10 & 0.11 & 0.09 & 0.08 & 0.08 & 0.06 & 0.12 & 0.08 & 0.06 \\
\hline$\widetilde{Q} 11$ & 0.08 & 0.22 & 0.21 & 0.10 & 0.11 & 0.17 & 0.12 & 0.15 & 0.10 & 0.11 & 0.10 & 0.11 & 0.09 & 0.10 & 0.13 \\
\hline$Q 12$ & 0.12 & 0.39 & 0.36 & 0.13 & 0.14 & 0.18 & 0.10 & 0.18 & 0.21 & 0.20 & 0.16 & 0.17 & 0.19 & 0.13 & 0.13 \\
\hline$\widetilde{Q} 13$ & 0.11 & 0.12 & 0.12 & 0.11 & 0.09 & 0.14 & 0.13 & 0.09 & 0.10 & 0.11 & 0.15 & 0.15 & 0.05 & 0.06 & 0.05 \\
\hline$Q 14$ & 0.17 & 0.14 & 0.10 & 0.10 & 0.11 & 0.09 & 0.11 & 0.09 & 0.75 & 0.65 & 0.21 & 0.15 & 0.17 & 0.13 & 0.18 \\
\hline$Q 15$ & 0.08 & 0.14 & 0.12 & 0.05 & 0.06 & 0.07 & 0.07 & 0.06 & 0.14 & 0.16 & 0.70 & 0.73 & 0.16 & 0.18 & 0.23 \\
\hline$Q 16$ & 1.00 & 0.10 & 0.11 & 0.08 & 0.06 & 0.09 & 0.10 & 0.08 & 0.11 & 0.12 & 0.12 & 0.06 & 0.05 & 0.07 & 0.08 \\
\hline$\widetilde{Q} 17$ & 0.10 & 1.00 & 0.82 & 0.09 & 0.11 & 0.10 & 0.09 & 0.11 & 0.15 & 0.15 & 0.10 & 0.09 & 0.12 & 0.08 & 0.11 \\
\hline$\widetilde{Q} 18$ & 0.11 & 0.82 & 1.00 & 0.08 & 0.09 & 0.09 & 0.10 & 0.09 & 0.11 & 0.13 & 0.11 & 0.11 & 0.12 & 0.08 & 0.12 \\
\hline Q19 & 0.08 & 0.09 & 0.08 & 1.00 & 0.75 & 0.63 & 0.65 & 0.72 & 0.12 & 0.13 & 0.10 & 0.07 & 0.67 & 0.67 & 0.56 \\
\hline$\widetilde{Q} 20$ & 0.06 & 0.11 & 0.09 & 0.75 & 1.00 & 0.49 & 0.43 & 0.51 & 0.13 & 0.13 & 0.09 & 0.08 & 0.48 & 0.49 & 0.34 \\
\hline$Q 21$ & 0.09 & 0.10 & 0.09 & 0.63 & 0.49 & 1.00 & 0.67 & 0.55 & 0.15 & 0.20 & 0.08 & 0.07 & 0.60 & 0.38 & 0.40 \\
\hline$\widetilde{Q} 22$ & 0.10 & 0.09 & 0.10 & 0.65 & 0.43 & 0.67 & 1.00 & 0.52 & 0.17 & 0.19 & 0.07 & 0.07 & 0.48 & 0.46 & 0.43 \\
\hline$Q 23$ & 0.08 & 0.11 & 0.09 & 0.72 & 0.51 & 0.55 & 0.52 & 1.00 & 0.13 & 0.14 & 0.10 & 0.07 & 0.59 & 0.50 & 0.44 \\
\hline$\widetilde{Q} 24$ & 0.11 & 0.15 & 0.11 & 0.12 & 0.13 & 0.15 & 0.17 & 0.13 & 1.00 & 0.78 & 0.21 & 0.15 & 0.20 & 0.18 & 0.17 \\
\hline$\widetilde{Q} 25$ & 0.12 & 0.15 & 0.13 & 0.13 & 0.13 & 0.20 & 0.19 & 0.14 & 0.78 & 1.00 & 0.22 & 0.17 & 0.13 & 0.15 & 0.14 \\
\hline
\end{tabular}


Table A3. Cont.

\begin{tabular}{|c|c|c|c|c|c|c|c|c|c|c|c|c|c|c|c|}
\hline & $Q 16$ & $Q 17$ & $Q 18$ & $Q 19$ & $Q 20$ & $Q 21$ & $Q 22$ & $Q 23$ & $Q 24$ & $Q 25$ & $Q 26$ & $Q 27$ & $Q 28$ & $Q 29$ & $Q 30$ \\
\hline$Q 26$ & 0.12 & 0.10 & 0.11 & 0.10 & 0.09 & 0.08 & 0.07 & 0.10 & 0.21 & 0.22 & 1.00 & 0.76 & 0.17 & 0.19 & 0.28 \\
\hline$Q 27$ & 0.06 & 0.09 & 0.11 & 0.07 & 0.08 & 0.07 & 0.07 & 0.07 & 0.15 & 0.17 & 0.76 & 1.00 & 0.14 & 0.17 & 0.25 \\
\hline$\tilde{Q}^{28}$ & 0.05 & 0.12 & 0.12 & 0.67 & 0.48 & 0.60 & 0.48 & 0.59 & 0.20 & 0.13 & 0.17 & 0.14 & 1.00 & 0.70 & 0.72 \\
\hline$\widetilde{Q} 29$ & 0.07 & 0.08 & 0.08 & 0.67 & 0.49 & 0.38 & 0.46 & 0.50 & 0.18 & 0.15 & 0.19 & 0.17 & 0.70 & 1.00 & 0.66 \\
\hline$\widetilde{Q} 30$ & 0.08 & 0.11 & 0.12 & 0.56 & 0.34 & 0.40 & 0.43 & 0.44 & 0.17 & 0.14 & 0.28 & 0.25 & 0.72 & 0.66 & 1.00 \\
\hline Q31 & 0.66 & 0.11 & 0.12 & 0.16 & 0.12 & 0.09 & 0.06 & 0.13 & 0.11 & 0.11 & 0.13 & 0.09 & 0.14 & 0.13 & 0.16 \\
\hline Q32 & 0.66 & 0.10 & 0.11 & 0.20 & 0.15 & 0.13 & 0.11 & 0.15 & 0.10 & 0.09 & 0.17 & 0.12 & 0.20 & 0.19 & 0.19 \\
\hline Q33 & 0.13 & 0.13 & 0.13 & 0.17 & 0.17 & 0.14 & 0.14 & 0.16 & 0.09 & 0.07 & 0.11 & 0.11 & 0.20 & 0.15 & 0.15 \\
\hline Q34 & 0.07 & 0.08 & 0.10 & 0.08 & 0.07 & 0.09 & 0.08 & 0.11 & 0.07 & 0.08 & 0.06 & 0.07 & 0.09 & 0.08 & 0.07 \\
\hline Q35 & 0.09 & 0.11 & 0.09 & 0.09 & 0.07 & 0.08 & 0.07 & 0.08 & 0.10 & 0.10 & 0.09 & 0.11 & 0.08 & 0.07 & 0.06 \\
\hline Q36 & 0.07 & 0.11 & 0.10 & 0.12 & 0.15 & 0.14 & 0.12 & 0.10 & 0.10 & 0.09 & 0.11 & 0.07 & 0.10 & 0.12 & 0.06 \\
\hline Q37 & 0.09 & 0.07 & 0.06 & 0.08 & 0.07 & 0.11 & 0.14 & 0.09 & 0.09 & 0.09 & 0.08 & 0.08 & 0.03 & 0.07 & 0.05 \\
\hline$\widetilde{Q} 38$ & 0.09 & 0.09 & 0.10 & 0.09 & 0.11 & 0.07 & 0.10 & 0.10 & 0.09 & 0.08 & 0.08 & 0.07 & 0.09 & 0.09 & 0.08 \\
\hline Q39 & 0.11 & 0.11 & 0.11 & 0.08 & 0.06 & 0.08 & 0.08 & 0.09 & 0.10 & 0.09 & 0.13 & 0.11 & 0.07 & 0.07 & 0.08 \\
\hline$Q 40$ & 0.06 & 0.12 & 0.11 & 0.08 & 0.10 & 0.07 & 0.09 & 0.10 & 0.08 & 0.08 & 0.08 & 0.07 & 0.05 & 0.08 & 0.09 \\
\hline Q41 & 0.09 & 0.09 & 0.09 & 0.08 & 0.13 & 0.07 & 0.06 & 0.09 & 0.08 & 0.09 & 0.09 & 0.09 & 0.09 & 0.08 & 0.07 \\
\hline$Q 42$ & 0.13 & 0.08 & 0.11 & 0.10 & 0.10 & 0.08 & 0.10 & 0.09 & 0.09 & 0.11 & 0.10 & 0.11 & 0.13 & 0.10 & 0.12 \\
\hline$\widetilde{Q} 43$ & 0.09 & 0.13 & 0.12 & 0.08 & 0.08 & 0.06 & 0.09 & 0.08 & 0.11 & 0.11 & 0.09 & 0.11 & 0.12 & 0.11 & 0.12 \\
\hline
\end{tabular}

Table A4. The values of the Cramer's V coefficient for questions $Q 31-Q 43$ (questions numbers $(Q)$ according to the Appendix A).

\begin{tabular}{|c|c|c|c|c|c|c|c|c|c|c|c|c|c|}
\hline & Q31 & Q32 & Q33 & Q34 & Q35 & Q36 & Q37 & Q38 & Q39 & $Q 40$ & $Q 41$ & $Q 42$ & $Q 43$ \\
\hline$Q 1$ & 0.09 & 0.11 & 0.16 & 0.09 & 0.09 & 0.14 & 0.17 & 0.23 & 0.11 & 0.09 & 0.12 & 0.14 & 0.12 \\
\hline$Q 2$ & 0.06 & 0.06 & 0.06 & 0.08 & 0.06 & 0.10 & 0.13 & 0.06 & 0.08 & 0.08 & 0.06 & 0.06 & 0.08 \\
\hline$Q 3$ & 0.08 & 0.07 & 0.06 & 0.04 & 0.14 & 0.11 & 0.15 & 0.23 & 0.11 & 0.09 & 0.06 & 0.20 & 0.23 \\
\hline$Q 4$ & 0.11 & 0.07 & 0.17 & 0.05 & 0.20 & 0.04 & 0.11 & 0.21 & 0.07 & 0.08 & 0.12 & 0.21 & 0.24 \\
\hline Q5 & 0.07 & 0.07 & 0.13 & 0.10 & 0.08 & 0.06 & 0.11 & 0.08 & 0.08 & 0.10 & 0.08 & 0.11 & 0.07 \\
\hline Q6 & 0.10 & 0.12 & 0.16 & 0.12 & 0.16 & 0.12 & 0.14 & 0.16 & 0.11 & 0.11 & 0.13 & 0.16 & 0.14 \\
\hline$\widetilde{Q} 7$ & 0.14 & 0.10 & 0.19 & 0.09 & 0.10 & 0.09 & 0.11 & 0.09 & 0.08 & 0.11 & 0.16 & 0.18 & 0.11 \\
\hline$\widetilde{Q} 8$ & 0.18 & 0.17 & 0.09 & 0.11 & 0.05 & 0.11 & 0.12 & 0.09 & 0.07 & 0.13 & 0.10 & 0.11 & 0.09 \\
\hline Q9 & 0.06 & 0.04 & 0.10 & 0.10 & 0.12 & 0.09 & 0.07 & 0.13 & 0.12 & 0.13 & 0.11 & 0.16 & 0.15 \\
\hline Q10 & 0.16 & 0.16 & 0.10 & 0.09 & 0.09 & 0.09 & 0.11 & 0.10 & 0.07 & 0.08 & 0.08 & 0.12 & 0.12 \\
\hline Q11 & 0.07 & 0.06 & 0.10 & 0.10 & 0.13 & 0.09 & 0.08 & 0.11 & 0.11 & 0.08 & 0.09 & 0.10 & 0.10 \\
\hline Q12 & 0.07 & 0.10 & 0.12 & 0.11 & 0.08 & 0.10 & 0.07 & 0.10 & 0.13 & 0.08 & 0.10 & 0.09 & 0.09 \\
\hline Q13 & 0.11 & 0.12 & 0.11 & 0.10 & 0.10 & 0.08 & 0.08 & 0.10 & 0.10 & 0.11 & 0.10 & 0.08 & 0.12 \\
\hline Q14 & 0.15 & 0.14 & 0.08 & 0.06 & 0.10 & 0.10 & 0.11 & 0.08 & 0.09 & 0.07 & 0.09 & 0.09 & 0.10 \\
\hline$\widetilde{Q} 15$ & 0.08 & 0.11 & 0.09 & 0.10 & 0.10 & 0.09 & 0.08 & 0.09 & 0.09 & 0.07 & 0.08 & 0.13 & 0.10 \\
\hline Q16 & 0.66 & 0.66 & 0.13 & 0.07 & 0.09 & 0.07 & 0.09 & 0.09 & 0.11 & 0.06 & 0.09 & 0.13 & 0.09 \\
\hline$\widetilde{Q} 17$ & 0.11 & 0.10 & 0.13 & 0.08 & 0.11 & 0.11 & 0.07 & 0.09 & 0.11 & 0.12 & 0.09 & 0.08 & 0.13 \\
\hline Q18 & 0.12 & 0.11 & 0.13 & 0.10 & 0.09 & 0.10 & 0.06 & 0.10 & 0.11 & 0.11 & 0.09 & 0.11 & 0.12 \\
\hline Q19 & 0.16 & 0.20 & 0.17 & 0.08 & 0.09 & 0.12 & 0.08 & 0.09 & 0.08 & 0.08 & 0.08 & 0.10 & 0.08 \\
\hline$\widetilde{Q} 20$ & 0.12 & 0.15 & 0.17 & 0.07 & 0.07 & 0.15 & 0.07 & 0.11 & 0.06 & 0.10 & 0.13 & 0.10 & 0.08 \\
\hline$\widetilde{Q} 21$ & 0.09 & 0.13 & 0.14 & 0.09 & 0.08 & 0.14 & 0.11 & 0.07 & 0.08 & 0.07 & 0.07 & 0.08 & 0.06 \\
\hline$Q 22$ & 0.06 & 0.11 & 0.14 & 0.08 & 0.07 & 0.12 & 0.14 & 0.10 & 0.08 & 0.09 & 0.06 & 0.10 & 0.09 \\
\hline$\widetilde{Q} 23$ & 0.13 & 0.15 & 0.16 & 0.11 & 0.08 & 0.10 & 0.09 & 0.10 & 0.09 & 0.10 & 0.09 & 0.09 & 0.08 \\
\hline$\widetilde{Q} 24$ & 0.11 & 0.10 & 0.09 & 0.07 & 0.10 & 0.10 & 0.09 & 0.09 & 0.10 & 0.08 & 0.08 & 0.09 & 0.11 \\
\hline$Q 25$ & 0.11 & 0.09 & 0.07 & 0.08 & 0.10 & 0.09 & 0.09 & 0.08 & 0.09 & 0.08 & 0.09 & 0.11 & 0.11 \\
\hline$Q 26$ & 0.13 & 0.17 & 0.11 & 0.06 & 0.09 & 0.11 & 0.08 & 0.08 & 0.13 & 0.08 & 0.09 & 0.10 & 0.09 \\
\hline$Q 27$ & 0.09 & 0.12 & 0.11 & 0.07 & 0.11 & 0.07 & 0.08 & 0.07 & 0.11 & 0.07 & 0.09 & 0.11 & 0.11 \\
\hline Q28 & 0.14 & 0.20 & 0.20 & 0.09 & 0.08 & 0.10 & 0.03 & 0.09 & 0.07 & 0.05 & 0.09 & 0.13 & 0.12 \\
\hline $\mathcal{Q}^{29}$ & 0.13 & 0.19 & 0.15 & 0.08 & 0.07 & 0.12 & 0.07 & 0.09 & 0.07 & 0.08 & 0.08 & 0.10 & 0.11 \\
\hline$\widetilde{Q} 30$ & 0.16 & 0.19 & 0.15 & 0.07 & 0.06 & 0.06 & 0.05 & 0.08 & 0.08 & 0.09 & 0.07 & 0.12 & 0.12 \\
\hline Q31 & 1.00 & 0.73 & 0.14 & 0.06 & 0.10 & 0.10 & 0.07 & 0.10 & 0.07 & 0.07 & 0.06 & 0.13 & 0.10 \\
\hline
\end{tabular}


Table A4. Cont.

\begin{tabular}{|c|c|c|c|c|c|c|c|c|c|c|c|c|c|}
\hline & Q31 & Q32 & Q33 & Q34 & Q35 & $Q 36$ & $Q 37$ & Q38 & Q39 & $Q 40$ & $Q 41$ & $Q 42$ & $Q 43$ \\
\hline Q32 & 0.73 & 1.00 & 0.13 & 0.07 & 0.07 & 0.06 & 0.08 & 0.06 & 0.08 & 0.13 & 0.07 & 0.13 & 0.09 \\
\hline Q33 & 0.14 & 0.13 & 1.00 & 0.27 & 0.06 & 0.09 & 0.08 & 0.10 & 0.06 & 0.34 & 0.37 & 0.32 & 0.32 \\
\hline Q34 & 0.06 & 0.07 & 0.27 & 1.00 & 0.11 & 0.09 & 0.07 & 0.12 & 0.11 & 0.20 & 0.21 & 0.13 & 0.17 \\
\hline Q35 & 0.10 & 0.07 & 0.06 & 0.11 & 1.00 & 0.12 & 0.08 & 0.11 & 0.11 & 0.08 & 0.10 & 0.13 & 0.09 \\
\hline Q36 & 0.10 & 0.06 & 0.09 & 0.09 & 0.12 & 1.00 & 0.23 & 0.09 & 0.11 & 0.08 & 0.10 & 0.08 & 0.08 \\
\hline Q37 & 0.07 & 0.08 & 0.08 & 0.07 & 0.08 & 0.23 & 1.00 & 0.25 & 0.12 & 0.10 & 0.08 & 0.10 & 0.13 \\
\hline Q38 & 0.10 & 0.06 & 0.10 & 0.12 & 0.11 & 0.09 & 0.25 & 1.00 & 0.25 & 0.10 & 0.11 & 0.29 & 0.32 \\
\hline Q39 & 0.07 & 0.08 & 0.06 & 0.11 & 0.11 & 0.11 & 0.12 & 0.25 & 1.00 & 0.06 & 0.09 & 0.11 & 0.10 \\
\hline$Q 40$ & 0.07 & 0.13 & 0.34 & 0.20 & 0.08 & 0.08 & 0.10 & 0.10 & 0.06 & 1.00 & 0.27 & 0.22 & 0.21 \\
\hline Q41 & 0.06 & 0.07 & 0.37 & 0.21 & 0.10 & 0.10 & 0.08 & 0.11 & 0.09 & 0.27 & 1.00 & 0.31 & 0.30 \\
\hline Q42 & 0.13 & 0.13 & 0.32 & 0.13 & 0.13 & 0.08 & 0.10 & 0.29 & 0.11 & 0.22 & 0.31 & 1.00 & 0.64 \\
\hline$\widetilde{Q} 43$ & 0.10 & 0.09 & 0.32 & 0.17 & 0.09 & 0.08 & 0.13 & 0.32 & 0.10 & 0.21 & 0.30 & 0.64 & 1.00 \\
\hline
\end{tabular}

\section{References}

1. Ligthart, T.N.; van Harmelen, T. Estimation of shadow prices of soil organic carbon depletion and freshwater depletion for use in LCA. Int. J. Life Cycle Ass. 2019, 24, 1602-1619. [CrossRef]

2. Boryczko, K.; Piegdoń, I.; Szpak, D.; Żywiec, J. Risk Assessment of Lack of Water Supply Using the Hydraulic Model of the Water Supply. Resources 2021, 10, 43. [CrossRef]

3. Nagpal, H.; Spriet, J.; Murali, M.K.; McNabola, A. Heat Recovery from Wastewater-A Review of Available Resource. Water 2021, 13, 1274. [CrossRef]

4. Shen, G.; Lee, Z.E.; Amadeh, A.; Zhang, K.M. A data-driven electric water heater scheduling and control system. Energ. Buildings 2021, 242, 110924. [CrossRef]

5. Sayegh, M.A.; Ludwińska, A.; Rajski, K.; Dudkiewicz, E. Environmental and energy saving potential from greywater in hotels. Sci. Total Environ. 2021, 761, 143220. [CrossRef] [PubMed]

6. Hong, B.; Howarth, R.W. Greenhouse gas emissions from domestic hot water: Heat pumps compared to most commonly used systems. Energy Sci. Eng. 2016, 4, 123-133. [CrossRef]

7. Javanmard, M.E.; Ghaderi, S.F.; Sangari, M.S. Integrating energy and water optimization in buildings using multi-objective mixed-integer linear programming. Sustain. Cities Soc. 2020, 62, 102409. [CrossRef]

8. Ravichandran, A.; Diaz-Elsayed, N.; Thomas, S.; Zhang, Q. An assessment of the influence of local conditions on the economic and environmental sustainability of drain water heat recovery systems. J. Clean. Prod. 2021, 279, 123589. [CrossRef]

9. Pochwat, K.; Kordana-Obuch, S.; Starzec, M.; Piotrowska, B. Financial Analysis of the Use of Two Horizontal Drain Water Heat Recovery Units. Energies 2020, 13, 4113. [CrossRef]

10. Li, Y.; Sun, F.; Zhang, Q.; Chen, X.; Yuan, W. Numerical Simulation Study on Structure Optimization and Performance Improvement of Hot Water Storage Tank in CHP System. Energies 2020, 13, 4734. [CrossRef]

11. Lin, W.M.; Chang, K.C.; Liu, Y.M.; Chung, K.M. Field Surveys of Non-Residential Solar Water Heating Systems in Taiwan. Energies 2012, 5, 258-269. [CrossRef]

12. Słyś, D.; Pochwat, K.; Czarniecki, D. An Analysis of Waste Heat Recovery from Wastewater on Livestock and Agriculture Farms. Resources 2020, 9, 3. [CrossRef]

13. Dudkiewicz, E.; Fidorów-Kaprawy, N. Hybrid Domestic Hot Water System Performance in Industrial Hall. Resources 2020, 9, 65. [CrossRef]

14. Marszal-Pomianowska, A.; Jensen, R.L.; Pomianowski, M.; Larsen, O.K.; Jørgensen, J.S.; Knudsen, S.S. Comfort of Domestic Water in Residential Buildings: Flow, Temperature and Energy in Draw-Off Points: Field Study in Two Danish Detached Houses. Energies 2021, 14, 3314. [CrossRef]

15. Stec, A.; Mazur, A. An Analysis of Eco-Technology Allowing Water and Energy Saving in an Environmentally Friendly House-A Case Study from Poland. Buildings 2019, 9, 180. [CrossRef]

16. Kordana, S. SWOT analysis of wastewater heat recovery systems application. E3S Web Conf. 2017, 17, 00042. [CrossRef]

17. Selimli, S.; Eljetlawi, I.A.M. The experimental study of thermal energy recovery from shower greywater. Energ. Source Part A 2020. [CrossRef]

18. El Hage, H.; Ramadan, M.; Jaber, H.; Khaled, M.; Olabi, A.G. A short review on the techniques of waste heat recovery from domestic applications. Energ. Source Part A 2020, 42, 3019-3034. [CrossRef]

19. Vranay, F.; Pirsel, L.; Kacik, R.; Vranayova, Z. Adaptation of HVAC Systems to Reduce the Spread of COVID-19 in Buildings. Sustainability 2020, 12, 9992. [CrossRef]

20. Wang, Q.; Dogot, T.; Yang, Y.; Jiao, J.; Shi, B.; Yin, C. From "Coal to Gas" to "Coal to Biomass": The Strategic Choice of Social Capital in China. Energies 2020, 13, 4171. [CrossRef]

21. Kida, M.; Ziembowicz, S.; Koszelnik, P. Application of an ultrasonic field, hydrogen peroxide and the fenton process in removing DEHP from bottom sediments. Desalin. Water Treat. 2020, 186, 309-316. [CrossRef] 
22. Zimmermann, M.; Felmeden, J.; Michel, B. Integrated Assessment of Novel Urban Water Infrastructures in Frankfurt am Main and Hamburg, Germany. Water 2018, 10, 211. [CrossRef]

23. Čeryová, D.; Bullová, T.; Turčeková, N.; Adamičková, I.; Moravčíková, D.; Bielik, P. Assessment of the Renewable Energy Sector Performance Using Selected Indicators in European Union Countries. Resources 2020, 9, 102. [CrossRef]

24. Dashtpeyma, M.; Ghodsi, R. Developing the resilient solar energy management system: A hybrid qualitative-quantitative approach. Int. J. Ambient Energy 2019. Available online: https://www.tandfonline.com/doi/abs/10.1080/01430750.2019.1630301 (accessed on 26 May 2021). [CrossRef]

25. Liu, H.; Zhang, H.; Javed, S. Long-Term Performance Measurement and Analysis of a Small-Scale Ground Source Heat Pump System. Energies 2020, 13, 4527. [CrossRef]

26. Golzar, F.; Nilsson, D.; Martin, V. Forecasting Wastewater Temperature Based on Artificial Neural Network (ANN) Technique and Monte Carlo Sensitivity Analysis. Sustainability 2020, 12, 6386. [CrossRef]

27. Diaz-Elsayed, N.; Rezaei, N.; Ndiaye, A.; Zhang, Q. Trends in the environmental and economic sustainability of wastewater-based resource recovery: A review. J. Clean. Prod. 2020, 265, 121598. [CrossRef]

28. Preisner, M.; Smol, M.; Szołdrowska, D. Trends, insights and effects of the Urban Wastewater Treatment Directive (91/271/EEC) implementation in the light of the Polish coastal zone eutrophication. Environ. Manag. 2021, 67, 342-354. [CrossRef]

29. Albaiyati, M.S.A.; Danca, P.; Neagu, A.; Sandu, M. Improving the efficiency of energy recovery from wastewater by using a double heat exchanger to protect the environment. IOP Conf. Ser. Earth Environ. Sci. 2021, 664, 012063. [CrossRef]

30. Manouchehri, R.; Collins, M.R. Modelling the Steady-State Performance of Coiled Falling-Film Drain Water Heat Recovery Systems Using Rated Data. Resources 2020, 9, 69. [CrossRef]

31. Murr, R.; Khaled, M.; Faraj, J.; Harika, E.; Abdulhay, B. Multi drain heat recovery system-Thermal modeling, parametric analysis, and case study. Energ. Buildings 2020, 228, 110447. [CrossRef]

32. Selimli, S.; Abajja, K.M.A. Recovery of greywater thermal energy with a wire on a tube heat exchanger attached to a dishwasher. Water Environ. Res. 2021. [CrossRef]

33. Selimli, S.; Karabas, T.; Taskin, Y.; Karatas, M.B. Experimental study of the performance of heat recovery by a fin and tube heat exchange tank attached to the dishwasher greywater line. Sustain. Energy Technol. Assess. 2019, 36, 100552. [CrossRef]

34. Schestak, I.; Spriet, J.; Styles, D.; Prysor Williams, A. Emissions down the drain: Balancing life cycle energy and greenhouse gas savings with resource use for heat recovery from kitchen drains. Energy Build. 2020, 271, 110988. [CrossRef]

35. Orynycz, O.; Tucki, K. Technology Management Leading to a Smart System Solution Assuring a Decrease of Energy Consumption in Recreational Facilities. Energies 2020, 13, 3425. [CrossRef]

36. Spriet, J.; McNabola, A. Decentralized Drain Water Heat Recovery: Interaction between Wastewater and Heating Flows on a Single Residence Scale. Proceedings 2018, 2, 583. [CrossRef]

37. Gou, X.; Fu, Y.; Shah, I.A.; Li, Y.; Xu, G.; Yang, Y.; Wang, E.; Liu, L.; Wu, J. Research on a Household Dual Heat Source Heat Pump Water Heater with Preheater Based on ASPEN PLUS. Energies 2016, 9, 1026. [CrossRef]

38. Todorović, D.; Tomić, M.; Bojanić, R.; Bajatović, D.; Anđelković, A.S. A comparative analysis of a heat pump application with grey wastewater source for domestic hot water preparation in hotels. J. Therm. Anal. Calorim. 2020, 141, 559-572. [CrossRef]

39. Sohail, U.; Kwiatek, C.; Fung, A.S.; Joksimovic, D. Techno-Economic Feasibility of Wastewater Heat Recovery for A Large Hospital in Toronto, Canada. Proceedings 2019, 23, 1. [CrossRef]

40. Zhu, J.J.; Wang, X.; Anderson, P.R. Modeling and spatial optimization of wastewater-source heat pump implementation in a wastewater collection system. Urban Water J. 2020, 16, 698-708. [CrossRef]

41. Gou, X.; Liu, S.; Fu, Y.; Zhang, Q.; Iram, S.; Liu, Y. Experimental Study on the Performance of a Household Dual-Source Heat Pump Water Heater. Energies 2018, 11, 2811. [CrossRef]

42. Wong, L.T.; Mui, K.W.; Zhou, Y. Carbon Dioxide Reduction Targets of Hot Water Showers for People in Hong Kong. Water 2017, 9, 576. [CrossRef]

43. Kordana, S.; Słyś, D. Analysis of profitability of using a heat recovery system from grey water discharged from the shower (case study of Poland). E3S Web Conf. 2017, 22, 00085. [CrossRef]

44. Siemiątkowski, P.; Tomaszewski, P.; Marszałek-Kawa, J.; Gierszewski, J. The Financing of Renewable Energy Sources and the Level of Sustainable Development of Poland's Provinces in the Area of Environmental Order. Energies 2020, 13, 5591. [CrossRef]

45. Krasko, V.A.; Doris, A. State distributed PV policies: Can low cost (to government) policies have a market impact? Energ Policy 2013, 59, 172-181. [CrossRef]

46. Zhao, L.; Zhang, W.; Wang, W. Recognition of Energy-Saving Influencing Factors of Construction Project Lifecycle Based on Knowledge Map. Int. J. Pattern Recogn. 2021, 35, 2159017. [CrossRef]

47. Tchórzewska-Cieślak, B.; Pietrucha-Urbanik, K.; Kuliczkowska, E. An Approach to Analysing Water Consumers' Acceptance of Risk-Reduction Costs. Energies 2020, 9, 132. [CrossRef]

48. Statistical Office in Rzeszów. Podkarpackie Regional Research Centre. Statistical Atlas of Podkarpackie Voivodeship; Statistics Poland-Spatial and Environmental Surveys Department: Rzeszow, Poland, 2018; Available online: https:/ /rzeszow.stat.gov.pl/ en/publications/other-studies/statistical-atlas-of-podkarpackie-voivodship,6,1.html (accessed on 16 May 2020).

49. Statistics Poland. Energy Consumption in Households in 2018; GUS: Warsaw, Poland, 2019; Available online: https://stat.gov.pl/en/ topics/environment-energy/ energy / energy-consumption-in-households-in-2018,2,5.html (accessed on 26 May 2021). 
50. European Energy Network. EnR Position Paper on Energy Poverty in the European Union; Italian National Agency for New Technologies, Energy and Sustainable Economic Development: Roma, Italy, 2019; Available online: Enr-network.org/wpcontent/uploads/ENERGYPOVERTY-EnRPositionPaper-January-2019.pdf (accessed on 31 May 2021).

51. Statistical Office in Rzeszów. Data of Podkarpackie Voivodship-June 2021. Available online: https:/ rzeszow.stat.gov.pl/en/ zakladka1/ (accessed on 27 August 2021).

52. Statistics Poland. The Situation of Households in 2020 on the Basis of Results of the Household Budget Survey; GUS: Warsaw, Poland, 2021; Available online: https:/ / stat.gov.pl/en/topics/living-conditions/living-conditions/the-situation-of-households-in-20 20-on-the-basis-of-results-of-the-household-budget-survey,12,20.html (accessed on 27 August 2021).

53. CASE-Doradcy Sp. z o.o. Wojewódzki Program Rozwoju Odnawialnych Źródeł Energii dla Województwa Podkarpackiego; 2013. Available online: http://www.bip.podkarpackie.pl/attachments/article/1020/874_1.pdf (accessed on 31 May 2021).

54. Keough, V.A.; Tanabe, P. Survey Research: An Effective Design for Conducting Nursing Research. J. Nurs. Res. 2011, 1, 37-44. [CrossRef]

55. Jones, T.L.; Baxter, M.A.J.; Khanduja, V. A quick guide to survey research. Ann. R. Coll. Surg. Engl. 2013, 95, 5-7. [CrossRef]

56. Iliopoulos, N.; Onuki, M.; Esteban, M. Shedding Light on the Factors That Influence Residential Demand Response in Japan. Energies 2021, 14, 2795. [CrossRef]

57. Gaspari, J.; Antonini, E.; Marchi, L.; Vodola, V. Energy Transition at Home: A Survey on the Data and Practices That Lead to a Change in Household Energy Behavior. Sustainability 2021, 13, 5268. [CrossRef]

58. Kim, J.; Nam, S. Do Household Time, Risk, and Social Preferences Affect Home Energy Retrofit Decisions in Korea? Sustainability 2021, 13, 4152. [CrossRef]

59. Applied Statistics Handbook. Coefficients for Measuring Association. Available online: http://www.acastat.com/statbook/ chisqassoc.htm (accessed on 6 August 2021).

60. Ip, K.; She, K.; Adeyeye, K. Life-cycle impacts of shower water waste heat recovery: Case study of an installation at a university sport facility in the UK. Environ. Sci. Pollut. R. 2018, 25, 19247-19258. [CrossRef]

61. Piotrowska, B.; Słyś, D.; Kordana-Obuch, S.; Pochwat, K. Critical Analysis of the Current State of Knowledge in the Field of Waste Heat Recovery in Sewage Systems. Resources 2020, 9, 72. [CrossRef]

62. Bertrand, A.; Aggoune, R.; Maréchal, F. In-building waste water heat recovery: An urban-scale method for the characterisation of water streams and the assessment of energy savings and costs. Appl. Energ. 2017, 192, 110-125. [CrossRef]

63. Mazhar, A.R.; Liu, S.; Shukla, A. A Key Review of Non-Industrial Greywater Heat Harnessing. Energies 2018, 11, 386. [CrossRef]

64. Kordana, S.; Słyś, D.; Dziopak, J. Rationalization of water and energy consumption in shower systems of single-family dwelling houses. J. Clean. Prod. 2014, 82, 58-69. [CrossRef]

65. Chudzicki, J.; Sosnowski, S. Instalacje Wodociagowe-Projektowanie, Wykonanie, Eksploatacja, 3rd ed.; Seidel-Przywecki: Warsaw, Poland, 2011.

66. The National Centre for Emissions Management (KOBiZE). Wskaźniki Emisyjności CO2, SO2, NOx, CO i Pyłu Całkowitego dla Energii Elektrycznej; IOŚ-PIB: Warszawa, Poland, 2020; Available online: https://www.kobize.pl/en/fileCategory/id/28/wskaznikiemisyjnosci (accessed on 5 August 2021).

67. The National Centre for Emissions Management (KOBiZE). Wartości opałowe (WO) i wskaźniki emisji CO2 (WE) w roku 2018 do raportowania w ramach Systemu Handlu Uprawnieniami do Emisji za rok 2021; IOŚ-PIB: Warszawa, Poland, 2020; Available online: https:/ / www.kobize.pl/pl/article/aktualnosci-2020/id/1783/wartosci-opalowe-wo-i-wskazniki-emisji-co2-we-wroku-2018-do-raportowania-w-ramach-systemu-handlu-uprawnieniami-do-emisji-za-rok-2021 (accessed on 5 August 2021).

68. Statistics Poland. Population. Size and Structure and Vital Statistics in Poland by Territorial Division in 2020. As of 31 December; Statistics Poland: Warsaw, Poland, 2021; Available online: https:/ /stat.gov.pl/obszary-tematyczne/ludnosc/ludnosc/ludnoscstan-i-struktura-ludnosci-oraz-ruch-naturalny-w-przekroju-terytorialnym-stan-w-dniu-31-12-2020,6,29.html (accessed on 8 July 2021).

69. Mazur, A. An assessment of the financial efficiency of a heat recovery system from graywater in a hotel. E3S Web of Conf. 2018, 45, 00051. [CrossRef]

70. Kimmels, A. Shower Heat Recovery: Overview of Commercially Available DWHR Systems, Meander Heat Recovery. 2011. Available online: www.meanderhr.com (accessed on 8 July 2019).

71. Kania, G.; Kwiecień, K.; Malinowski, M.; Gliniak, M. Analyses of the Life Cycles and Social Costs of CO2 Emissions of SingleFamily Residential Buildings: A Case Study in Poland. Sustainability 2021, 13, 6164. [CrossRef]

72. Ministry of Climate and Environment. Energy Policy of Poland until 2040; Ministry of Climate and Environment: Warsaw, Poland, 2021; Available online: https:/ / www.gov.pl/web/klimat/polityka-energetyczna-polski (accessed on 9 July 2021).

73. Patent Office of the Republic of Poland. Available online: https:/ / uprp.gov.pl/pl (accessed on 12 July 2021).

74. Tanha, K.; Fung, A.S.; Kumar, R. Simulation and experimental investigation of two hybrid solar domestic water heaters with drain water heat recovery. Int. J. Energy Res. 2015, 39, 1879-1889. [CrossRef]

75. Wallin, J.; Claesson, J. Analyzing the efficiency of a heat pump assisted drain water heat recovery system that uses a vertical inline heat exchanger. Sustain. Energy Technol. Assess. 2014, 8, 109-119. [CrossRef] 
76. Statistics Poland. Local Data Bank. Available online: https://bdl.stat.gov.pl/BDL/dane/podgrup/teryt (accessed on 12 July 2021).

77. Liebersbach, J.; Żabnieńska-Góra, A.; Polarczyk, I.; Sayegh, M.A. Feasibility of Grey Water Heat Recovery in Indoor Swimming Pools. Energies 2021, 14, 4221. [CrossRef] 